Key Words:

High Level Waste

Pumps

History

Retention:

Permanent

\title{
TNX/HLW LONG SHAFT PUMPS 1995-2000
}

\author{
C. L. Sharpe \\ D. B. Stefanko
}

JUNE 2001

Westinghouse Savannah River Company

Savannah River Site

Aiken, SC 29808

Prepared for the U.S. Department of Energy Under

Contract Number DE-AC09-96SR18500

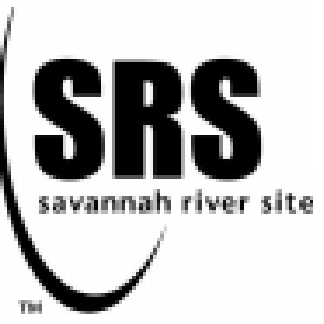


This document was prepared in conjunction with work accomplished under Contract No. DEAC09-96SR18500 with the U.S. Department of Energy.

\section{DISCLAIMER}

This report was prepared as an account of work sponsored by an agency of the United States Government. Neither the United States Government nor any agency thereof, nor any of their employees, makes any warranty, express or implied, or assumes any legal liability or responsibility for the accuracy, completeness, or usefulness of any information, apparatus, product or process disclosed, or represents that its use would not infringe privately owned rights. Reference herein to any specific commercial product, process or service by trade name, trademark, manufacturer, or otherwise does not necessarily constitute or imply its endorsement, recommendation, or favoring by the United States Government or any agency thereof. The views and opinions of authors expressed herein do not necessarily state or reflect those of the United States Government or any agency thereof.

This report has been reproduced directly from the best available copy.

Available for sale to the public, in paper, from: U.S. Department of Commerce, National Technical Information Service, 5285 Port Royal Road, Springfield, VA 22161

phone: (800) 553-6847

fax: (703) 605-6900

email: orders@ntis.fedworld.gov

online ordering: http://www.ntis.gov/support/index.html

Available electronically at http://www.osti.gov/bridge

Available for a processing fee to U.S. Department of Energy and its contractors, in paper, from: U.S. Department of Energy, Office of Scientific and Technical Information, P.O. Box 62, Oak Ridge, TN 37831-0062

phone: (865)576-8401

fax: (865)576-5728

email: reports@adonis.osti.gov 
Key Words:

High Level Waste

Pumps

History

Retention:

Permanent

\title{
TNX/HLW LONG SHAFT PUMPS 1995-2000
}

\author{
C. L. Sharpe \\ D. B. Stefanko
}

JUNE 2001

Westinghouse Savannah River Company

Savannah River Site

Aiken, SC 29808

Prepared for the U.S. Department of Energy Under

Contract Number DE-AC09-96SR18500

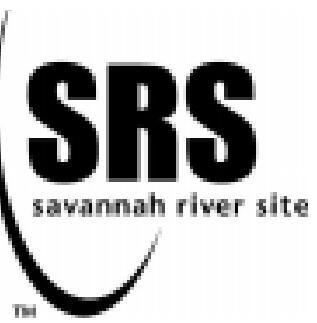




\section{REVIEWS AND APPROVALS}

C. L. Sharpe, Co-author, Waste Processing Technology

Date

David B. Stefanko, Co-author, Waste Processing Technology

Date

Robert Leishear, CST Engineering

Date

William B. Van Pelt, Level 4 Manager, Waste Processing Technology

Date

Eloy Saldivar, Level 4 Manager, Waste Removal Closure

Date

Steven Tibrea, Level 3 Manager, Waste Removal Projects

Date

Walter L. Tamosaitis, Level 3 Manager, Waste Processing Technology

Date 


\section{TABLE OF CONTENTS}

LIST OF FIGURES ......................................................................................................................iv

LIST OF TABLES ........................................................................................................................................ iv

LIST OF ACRONYMS.......................................................................................................................iv

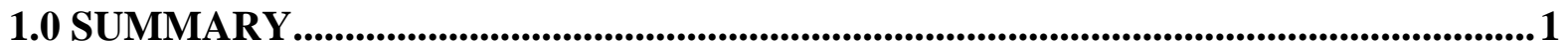

2.0 SUMMARY OF LONG SHAFT PUMP STATUS ............................................................3

3.0 SUBJECTS AFFECTING ALL PUMPS ..............................................................................5

3.1 ROTORDYNAMIC STUDIES .....................................................................................5

3.1.1 Rotordynamic Analysis Results - Journal vs. Tilt Pad Bearings...........................9

3.2 COLUMN RESONANCE ...................................................................................11

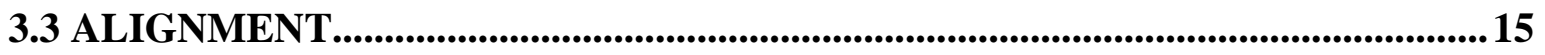

3.4 VIBRATION MEASUREMENTS .........................................................................................15

4.0 INDIVIDUAL PUMP PROGRAMS ............................................................................19

4.1 ORIGINAL WASTE REMOVAL PUMP DESCRIPTION ........................................19

4.2 ORIGINAL PUMP PROBLEMS .........................................................................19

4.3 TANK CONTAMINATION FROM ORIGINAL SEALS............................................20

4.4 HAZLETON PROTOTYPE FEED PUMP......................................................................21

4.5 TANK 48 RUN INS...........................................................................................................21

4.6 TANK 51 RUN INS - TANK 40 PUMPS (Hydraulic Unbalance and Vibration).21

4.7 TANK 40 REPLACEMENT QUADVOLUTE SLURRY PUMPS (S-5580)..........22

4.8 TANK 49 PUMPS ...........................................................................................................23

4.9 WEST VALLEY / FLOWAY TESTING ........................................................................23

4.10 HAZLETON TTP PERFORMANCE...........................................................................24

4.11 LPI WASTE REMOVAL SLURRY PUMPS - PART I...............................................25

4.12 EVAPORATOR FEED PUMP ...................................................................................28

4.13 ADVANCED DESIGN MIXER PUMP PROTOTYPE .............................................29

4.14 LPI WASTE REMOVAL SLURRY PUMPS - PART II ............................................32



6.0 RECOMMENDATIONS .............................................................................................................37

7.0 FUTURE WORK ...........................................................................................................................39

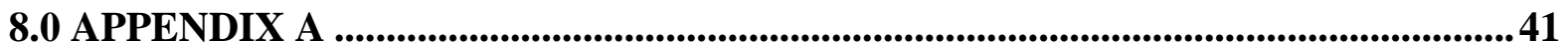

9.0 APPENDIX B ...................................................................................................................

10.0 APPENDIX C ................................................................................................................5

11.0 REFERENCES ................................................................................................................5 


\section{LIST OF FIGURES}

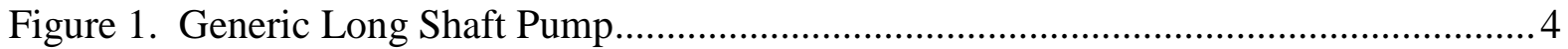

Figure 2. Tilt Pad Bearing Drawing .............................................................................. 7

Figure 3. Tilt Pad Bearing for Lawrence LPI91103 Mixer Pump .......................................... 8

Figure 4. Pipe Model vs. Measured Natural Frequency ......................................................... 12

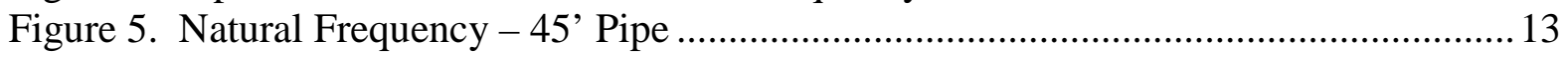

Figure 6. Effect of Variables on Natural Frequencies.......................................................... 14

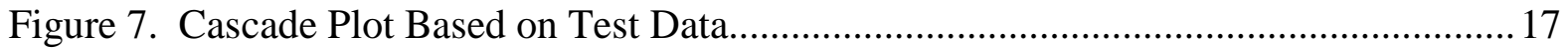

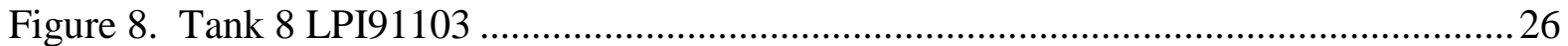

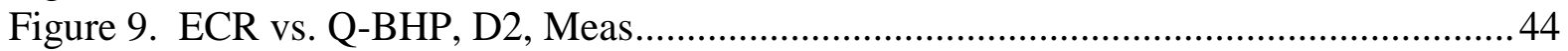

Figure 10. Impeller Profile or Shape vs. Specific Speed - Ns................................................. 45

\section{LIST OF TABLES}

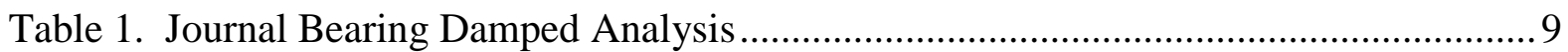

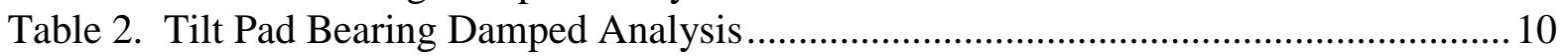

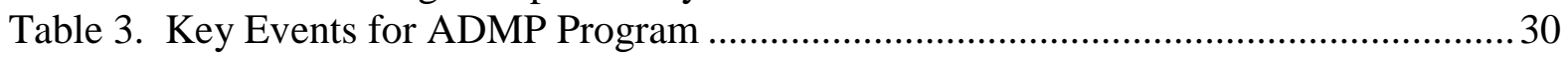

Table 4. Scoping Calculation for Pump Mixing at Constant HP ........................................... 46

Table 5. Scoping Calculation - ECR vs. Q at Constant BHP ................................................4

\section{LIST OF ACRONYMS}

$\begin{array}{ll}\text { ADE } & \text { Advective-Dispersive Equation } \\ \text { ADMP } & \text { Advanced Design Mixer Pump } \\ \text { ADRE } & \text { Automated Diagnostics for Rotating Equipment } \\ \text { BEP } & \text { Best Efficiency Point } \\ \text { BRA } & \text { Baseline Risk Assessment } \\ \text { CSI } & \text { Computational System, Incorporated } \\ \text { EFP } & \text { Evaporator Feed Pump } \\ \text { ESP } & \text { Extended sludge processing } \\ \text { FEA } & \text { Finite Element Analysis } \\ \text { LPI } & \text { Lawrence Pumps, Inc. } \\ \text { NDT } & \text { Non-Destructive Testing } \\ \text { QVSP } & \text { Quad-volute slurry pump - Sulzer Bingham } \\ \text { SBI } & \text { Sulzer Bingham, Incorporated } \\ \text { TTP } & \text { Telescoping Transfer Pump } \\ \text { WP } & \text { Waste removal }\end{array}$




\subsection{SUMMARY}

Problems with long shaft pumps are becoming clearer due to increased use, better instrumentation, more analysis, and increased testing activity. The problems are with reliability and not with hydraulic performance. The root cause of reliability problems is usually excessive vibration caused by design. The outlook for satisfactory pumps is improved as understanding of problems increases. Promising developments are emerging such as the tilt pad bearing. Alternative configurations, such as gas filled columns and submerged motor pumps, will require development. Continued development, in general, should be expected due to changing technology and industry changes. 
This page intentionally left blank.

Page 2 of 58 


\subsection{SUMMARY OF LONG SHAFT PUMP STATUS}

This report describes thirteen distinct pump programs starting with leakage of original mixer pumps in the 1980s and ending with the testing of tilt pad bearings now in progress. Eight of the programs occurred from 1996 to 2000. All involve long shaft pumps; all involve testing at TNX; and all involve a problem of some kind. The common technical issue among the activities is vibration and shaft (or rotor) instability due to journal bearings. In every case, excessive shaft vibration is a reasonable and probable explanation for some or all of the problems. Figure 1 shows a generic long shaft pump.

Recognition of this root cause has been slow. Suppliers have been helpful, but they do not recognize the root cause. The recognition of journal bearings as a problem root cause has come with help from outside consultants, specifically:

- Mark Corbo - No Bull Engineering

- Wes Franklin - Bently-Nevada

- Dave Hobbins - Westinghouse Electro-Mechanical Division (WEMD)

- Bill Marscher - Mechanical Solutions

The acquisition and use of modern vibration analysis equipment has been essential. The limited range of length-to-diameter ratio of waste tank pumps is a factor in the consistent problems. Column natural frequencies with low vibrational modes are directly related to the length-to-diameter ratio. Low column vibrational modes are more easily excited by shaft instability. Three notable problem causes are evident in addition to vibration, but none is as universal or as consistent as the rotor critical speed or shaft whirl instability problem.

1. Hydraulic unbalance occurred due to non-uniformity of impellers and casings made by sand casting. It was especially severe in the mixed flow impeller of the quadvolute mixer pumps used in Tanks 51, 49 and 40. It is moderate in the casings of the Lawrence waste removal pumps - thirteen pumps - nine can be changed if justified.

2. Seal design change - using a backup bushing and omitting a pumping ring - was a serious problem in the $3 \mathrm{H}$ evaporator feed pump. It may be a negligible to minor problem in the Lawrence waste removal pumps.

3. Column alignment is a difficult -to-control variable that had an effect with journal bearings on the $3 \mathrm{H}$ evaporator feed pump and probably is a factor in the Lawrence waste removal pump to pump variability. It may be a less important issue if tilt pad bearings are used. 


\section{GENERIC LONG SHAFT PUMP}

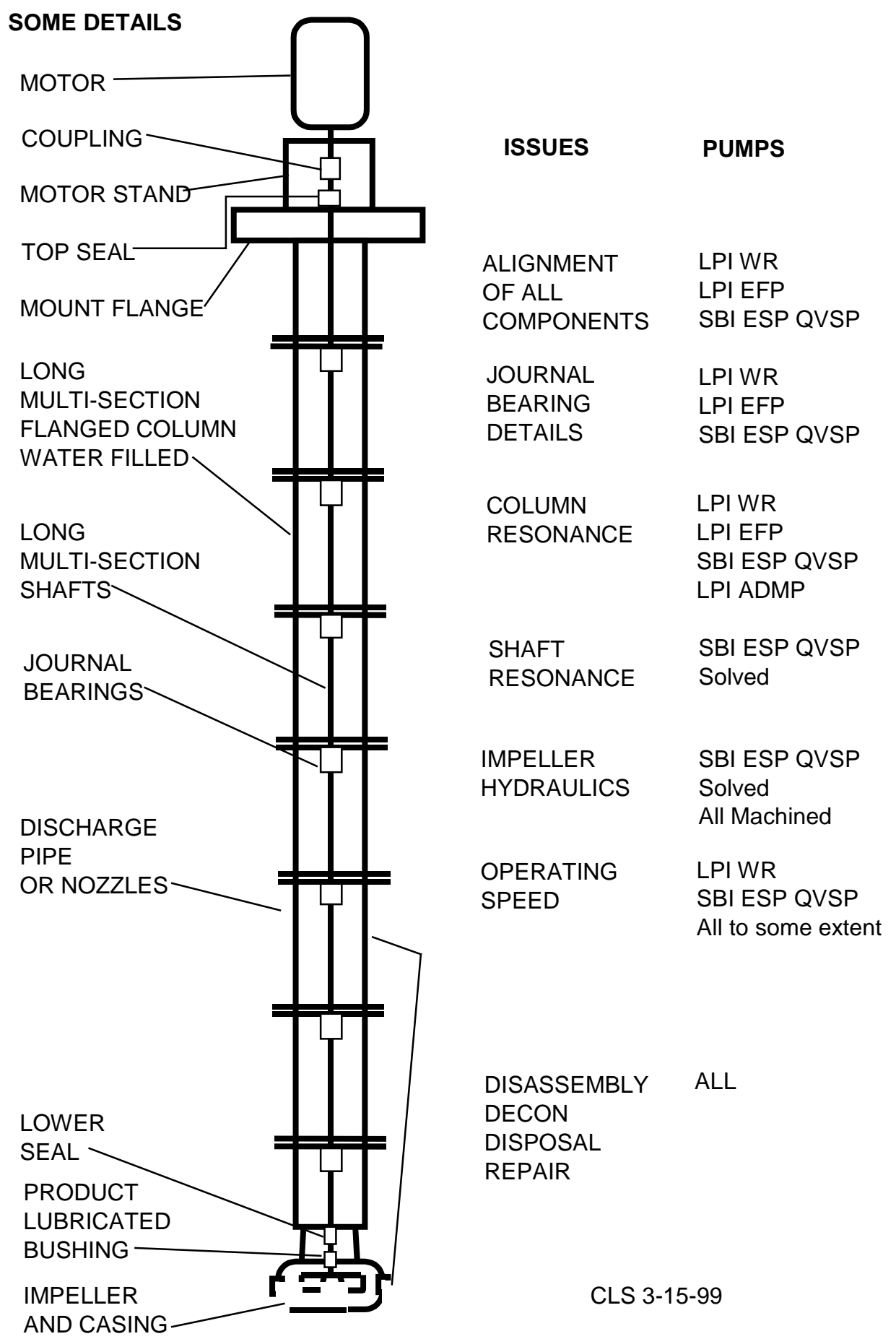

Figure 1. Generic Long Shaft Pump 
WSRC-TR-2001-00313

\subsection{SUBJECTS AFFECT ING ALL PUMPS}

\subsection{ROTORDYNAMIC ST UDIES}

Three two-level finite element rotordynamic studies have been completed on two SRS pump models. ${ }^{123}$ One of the three (Corbo) is actually very thorough and suitable for use in the design phase of a pump.

Wes Franklin of Bently Nevada did two studies - the evaporator feed pump and the Lawrence waste removal mixer pump. A two-level model means that both the column and the rotor (shaft and impeller) are analyzed. The column and rotor are connected by the bearings. Bearings have a stiffness and a damping coefficient. Franklin used a simple pipe model for the column and a detailed rotor model based on shaft design. He adjusted the bearing stiffness to match measured data.

The study analyzed increased bearing stiffness, unbalance response, and different unbalance locations. The model is axisymmetric. Franklin's results were:

- The shafts are unstable.

- Bearing stiffness is low.

- Increased journal bearing stiffness will not eliminate instability.

- Different unbalance locations just shift the location of the problem.

- A different bearing design is needed.

A specific bearing change was not requested or included in the study. The EFP study showed that a tighter clearance on the product lube bearing would be helpful to that bearing, but the product lube bearing does not solve the problems in the rotor. The results for the evaporator feed pump and the mixer pump were similar because the designs are similar.

Mark Corbo of No Bull Engineering, Guilderland, NY, did a study on the Lawrence mixer pump. SRS funded this second study on the same pump to compare the results and learn more about what to expect from a study. Corbo approached the construction of the finite element model in a different manner than Wes Franklin. Corbo used models for the rotor and column based entirely on design details. His column model has as many elements as the rotor model. He also calculated bearing stiffness from bearing dimensions using a separate computer code.

The first try at bearing stiffness was unsatisfactory - the pump model using this input did not agree well with measured data. Corbo analyzed and modified the bearing code to produce bearing stiffness that represented the SRS bearing condition - specifically, a flooded, pressurized bearing as opposed to ambient pressure bearings. This seems to have been pioneering work. With lower bearing stiffness, agreement was improved, but not satisfactory. The sealed, pressurized column was again the cause of disagreement. 
Other vertical pumps have an opening at the impeller end. Modeling practice is to assume only a portion of the column water moves with the vibrating column. With a sealed column, all of the column water moves with the column. This may also be pioneering work in the modeling area. With this change, the agreement with measured data was very good.

Corbo modeled a zero rpm case to compare to impact tests, undamped cases, and damped cases representing the use of tilt pad bearings instead of journal bearings. He also did an unbalance response case, which can be compared to column vibration measurements. Most results were the same as Franklin's. The shaft is unstable, higher bearing stiffness is not a solution, and damping is required. Tilt pad bearings do not eliminate the response to column natural frequencies and no bearing is expected to. (See Figure 2 and Figure 3.)

Corbo's work is significant because it proceeded from design details. With the knowledge of flooded bearings and sealed columns, this means that Corbo's methods allow the prediction of performance from design drawings. Preliminary design can be evaluated before costly fabrication and testing. Corbo ${ }^{4}$ published an article that describes the construction of the finite element model. This article combined with his report on the Lawrence mixer pumps enables Corbo or another analyst to duplicate the results on future or existing, but unstudied, pumps. The advantage to using Corbo's services is his SRS pump experience.

For about two years, tilt pad bearings have been mentioned as an improvement. Corbo and Franklin agree that bearings need more stiffness and damping. Journal bearings have low stiffness and no damping. Ball bearings have high stiffness and no damping. Tilt pad bearings have moderate (adequate) stiffness and good damping. They appear to be a logical improvement to SRS vertical pumps.

SRS specifications have always contained a requirement that the shafting have no critical speeds below the operating speed. The standard lateral critical speed calculation is to assume a length of shaft equal to bearing separation - rigidly supported at both ends. ${ }^{5}$ These calculations give results in the 2000 to $3000 \mathrm{rpm}$ range. The shafts are not rigidly supported but this is the industry standard. Finite element analysis shows first rotor critical speeds in the 500 to $700 \mathrm{rpm}$ range - a difference of a factor of four - and well below the operating speed. The first rotor critical is coincidental to the onset of shaft whirl in a long-shaft, vertical pump with journal bearings. Once established, it increases sharply with speed increases.

Understanding the principles of critical speed calculations is a recent lesson learned. During the Tank 51 replacement pump testing in 1995, the standard (inaccurate) calculation was used by the supplier in the problem analysis; no one at SRS knew the difference. The same basic pump design had finite element analysis done by the supplier as part of their internal test failure analysis in 1996 (Project S-5580). The rotor critical speeds, if calculated, were not disclosed to SRS; only the pertinent column critical speeds (or natural frequencies) were disclosed. 


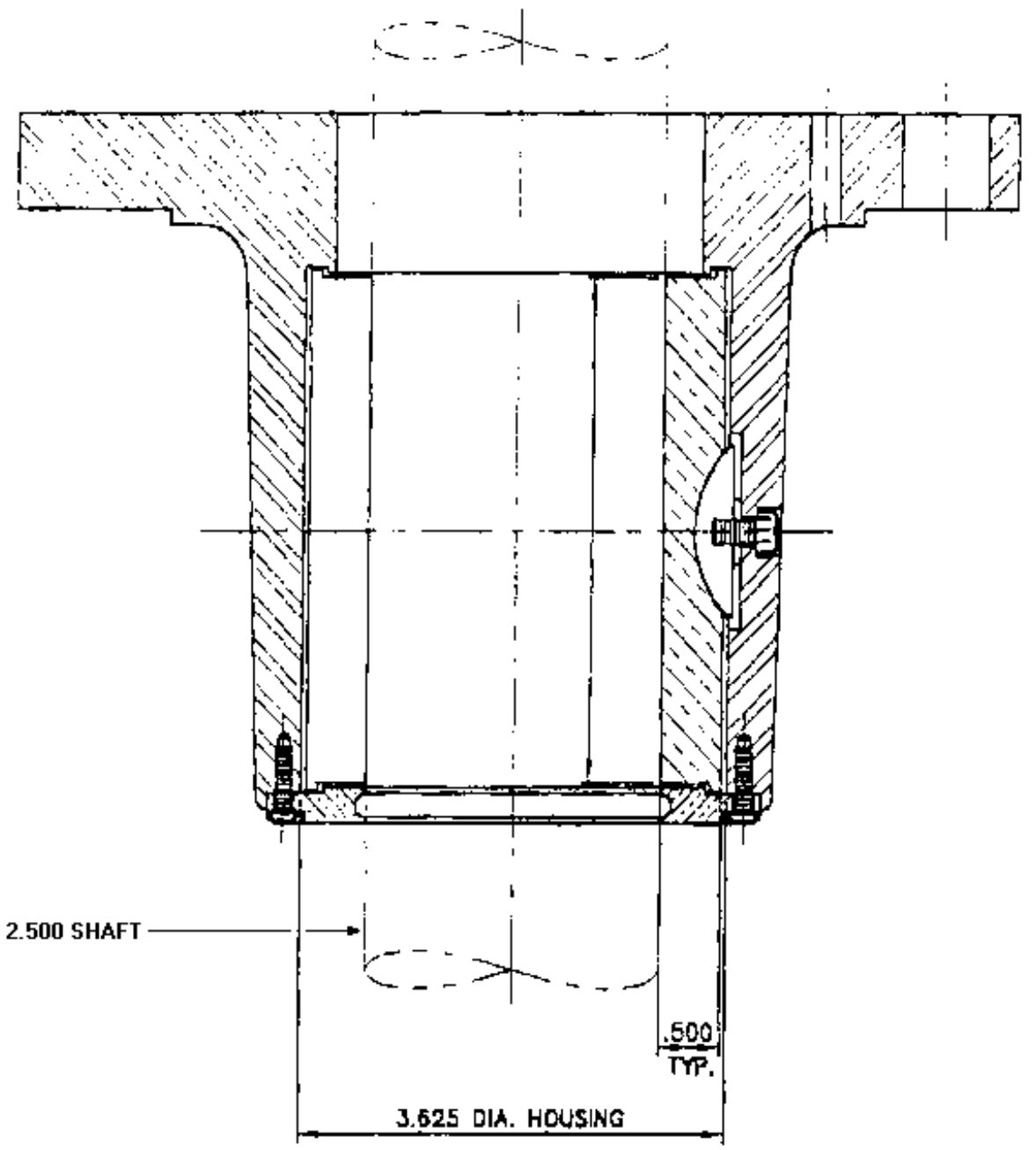

Tilt Pad Bearing Drawing - not to scale For Lawrence LPI 91103 mixer pump

Designed - Mark Corbo

Built - Turbo Components Houston TX

Used existing housing - modified

Waukesha 88 pads - one of four shown in section view on right

2 mils diametric clearance. Pads tilt radially and axially.

Figure 2. Tilt Pad Bearing Drawing 


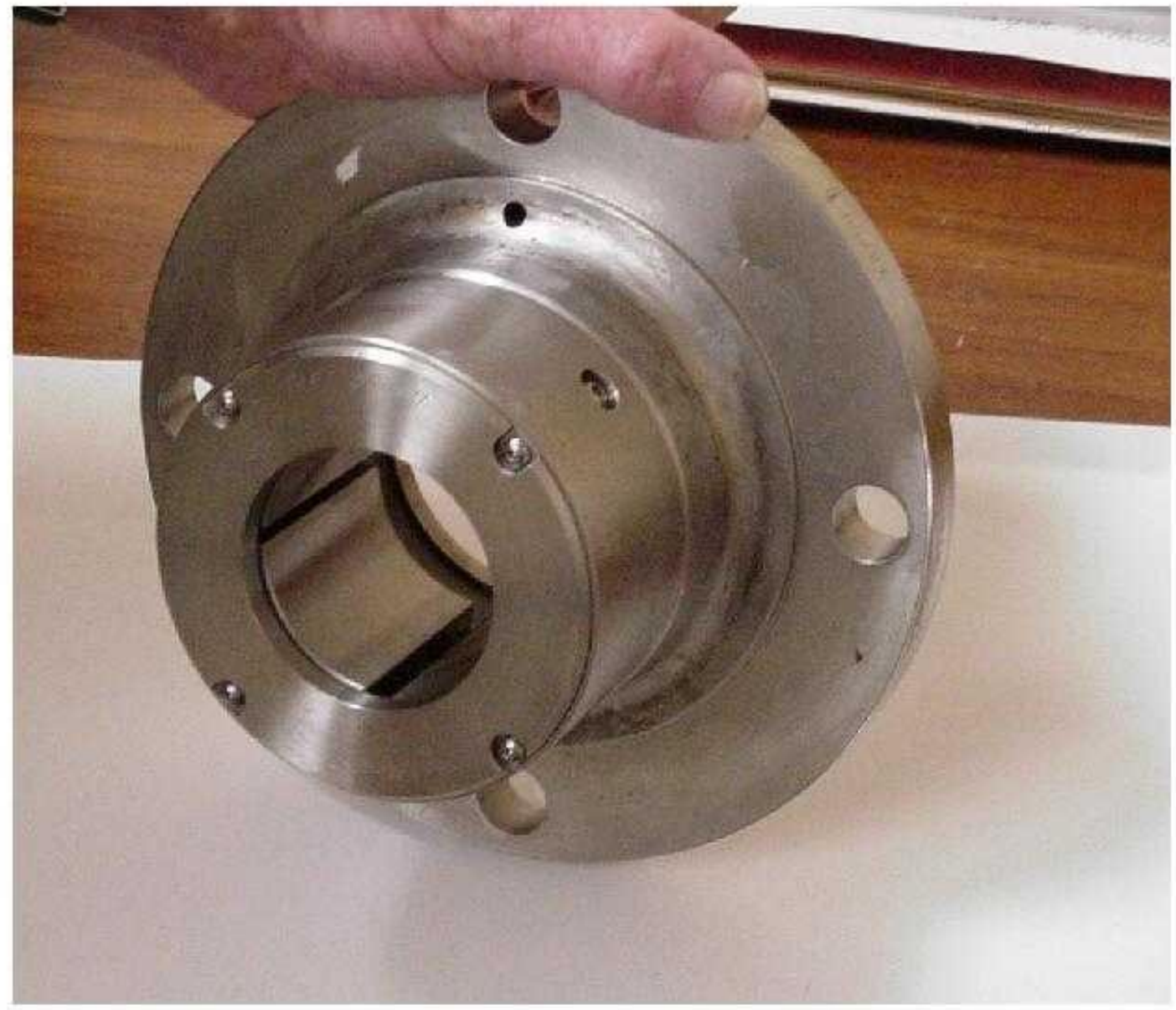

Tilt Pad Bearing for Lawrence LPI 91103 mixer pump.

Designed-Mark Corbo. Built - Turbo Components Houston TX

Used existing housing - modified. Pads Waukesha 88

Figure 3. Tilt Pad Bearing for Lawrence LPI91103 Mixer Pump 


\subsubsection{Rotordynamic Analysis Results - Journal vs. Tilt Pad Bearings}

Table 1. Journal Bearing Damped Analysis

\begin{tabular}{|l|l|c|l|}
\hline $\begin{array}{l}\text { Damped } \\
\text { Mode No. }\end{array}$ & Description & RPM & Log Decrement \\
\hline 1 & Rotor and Column & 55 & -0.0036 \\
\hline 2 & Rotor and Column & 347 & -0.0089 \\
\hline 3 & Rotor - Pump End & 645 & -0.0447 \\
\hline 4 & Rotor - Total & 759 & -0.0746 \\
\hline 5 & Rotor and Column & 764 & -0.1253 \\
\hline 6 & Rotor - Total & 773 & -0.2352 \\
\hline 7 & Rotor - Center & 790 & -0.1684 \\
\hline 8 & Rotor and Column & 968 & +0.0906 \\
\hline 9 & Rotor and Column & 1798 & +0.0849 \\
\hline 10 & Rotor - Motor End & 2364 & +0.0436 \\
\hline
\end{tabular}

In Table 1, RPM is the onset of shaft instability in a particular mode shape. Negative log decrement means the excitation from the rotor (shaft) adds to the column vibration. Vibration increases until the column bending forces are high enough to stop the motion. All are critical speeds. Positive log decrement means the phase angles are such as to damp the motion. These also are critical speeds. Log decrement values above +0.10 represent adequate damping, while values greater than +0.30 represent well-damped conditions. Modes 7, 6, and 5 initiate and sustain shaft whirl and they are strongly negative -0.12 to -0.23 . Modes 8 and 9 are problems if operating speed is $1800 \mathrm{rpm}$. Although positively damped, the damping is weak. 
Table 2. Tilt Pad Bearing Damped Analysis

\begin{tabular}{|l|l|c|l|}
\hline $\begin{array}{l}\text { Damped } \\
\text { Mode No. }\end{array}$ & Description & RPM & Log Decrement \\
\hline 1 & Rotor and Column & 55 & -0.0010 \\
\hline 2 & Rotor and Column & 347 & -0.0041 \\
\hline 3 & Rotor - Pump End & 775 & +0.6104 \\
\hline 4 & Rotor and Column & 963 & +0.0466 \\
\hline 5 & Rotor and Column & 1798 & +0.0524 \\
\hline 6 & Rotor - Motor End & 2358 & +0.0159 \\
\hline
\end{tabular}

For the tilt pad bearing case in Table 2, Mode 3 is rotor only but is highly damped. Modes 4 and 5 are positively damped but not strongly, therefore operation at $1800 \mathrm{rpm}$ is not advised. The $1800 \mathrm{rpm}$ value needs to be experimentally validated. However, it may be acceptable for short periods - near end of tank cleaning, for example. Operation at $2000 \mathrm{rpm}$ may be acceptable. Notice that all the negatively-damped modes except the two low rpm column modes have disappeared.

Neither of the above two analysis summaries actually match a real pump because of preloading from small misalignment. The preload may help or hurt the journal bearings. Minor misalignment has less effect on the pre-load effects to the tilt-pad bearings because they have two orders of magnitude higher bearing stiffness. 
WSRC-TR-2001-00313

\subsection{COLUMN RESONANCE}

High vibration at certain speeds on long-shaft pumps has been recognized from the outset. Operation at these speeds has been avoided. The Advanced Design Mixer Pump (ADMP) has a column natural frequency just below the design speed in a shortened configuration. Sulzer Bingham Waste Removal pumps and Hazleton Telescoping Transfer Pumps do not have column natural frequencies at the design speed. Quantitative identification of natural frequencies occurred when modern vibration analysis equipment was acquired at SRS in 1994-1995. Some vibration analyzers can perform impact tests - done with the pump stopped. The Bently Nevada Automated Diagnostics for Rotating Equipment (ADRE) analyzer can produce Bode or Nyquist plots which show critical speeds while running. (TNX chooses Bode plots; both show the same information - one is rectilinear and one is polar.)

Critical speeds cover not only column natural frequencies but shaft critical speeds or instabilities as well. It is best to use both impact tests and dynamic data. Long-shaft pumps have three to five - usually four - column natural frequencies below or near the operating speed. Two different models of Lawrence pumps have column natural frequencies at $1 / 2 \mathrm{X}$ and $1 \mathrm{X}$ the operating speeds - the worst possible case in a pump with journal bearings. The waste removal mixer pump $(1 / 2 \mathrm{X})$ is excited by the shaft whirl and the evaporator feed pump $(1 \mathrm{X})$ is excited by unbalance.

These critical speed occurrences are accidents of design. Pump suppliers and rotordynamic experts regard critical speeds, including those dominated by column natural frequencies, as requiring complex calculations to predict. Such calculations are not done unless specified. However, HLW/TNX requested Charles McKeel of Systems Engineering to prepare a simple mathematical pipe model, one end fixed, to use for sensitivity studies. (See Appendix A.) The model was generated from standard vibration equations available in most vibration textbooks. This model has proved to be reasonably accurate in predicting natural frequencies up through Mode 4. (See Figure 4.) The pipe model has reasonable agreement with impact tests and Bode plots for SRS pumps. It predicts Mode 5 with more error compared to finite element analysis and impact tests. Bode plots do not go as high as Mode 5, i.e. operating speeds are lower. The pipe model is not a replacement for finite element analysis (FEA), but it has its uses.

A large number of variations in parameters can quickly be assessed. Such calculations would be too time consuming to do with FEA because of mere curiosity. Appendix B figures show impact data, Bode data, and model data for SRS pumps. In addition, two sensitivity studies are shown. One covers pumps that are 45 feet long for column diameters from 6" to 20" any reasonable diameter. Another uses column diameters of 10", 14" and 16" (actual pump sizes) and studies the effect of length, weight (air filled vs. water filled), and pipe schedule. These studies show no design change eliminates the natural frequencies; design changes just change the frequency. Future purchases should use the pipe model and finite element analysis in design evaluation to avoid resonance problems at design operating speed. Examples are shown in Figure 5 and Figure 6. 
Pipe Model v. Measured Natural Frequency

$\bullet \mathrm{LPI}$ - EFP $\triangle \mathrm{TP} 45 \times \mathrm{TP} 40+\mathrm{QV} \bullet \mathrm{ADM}$

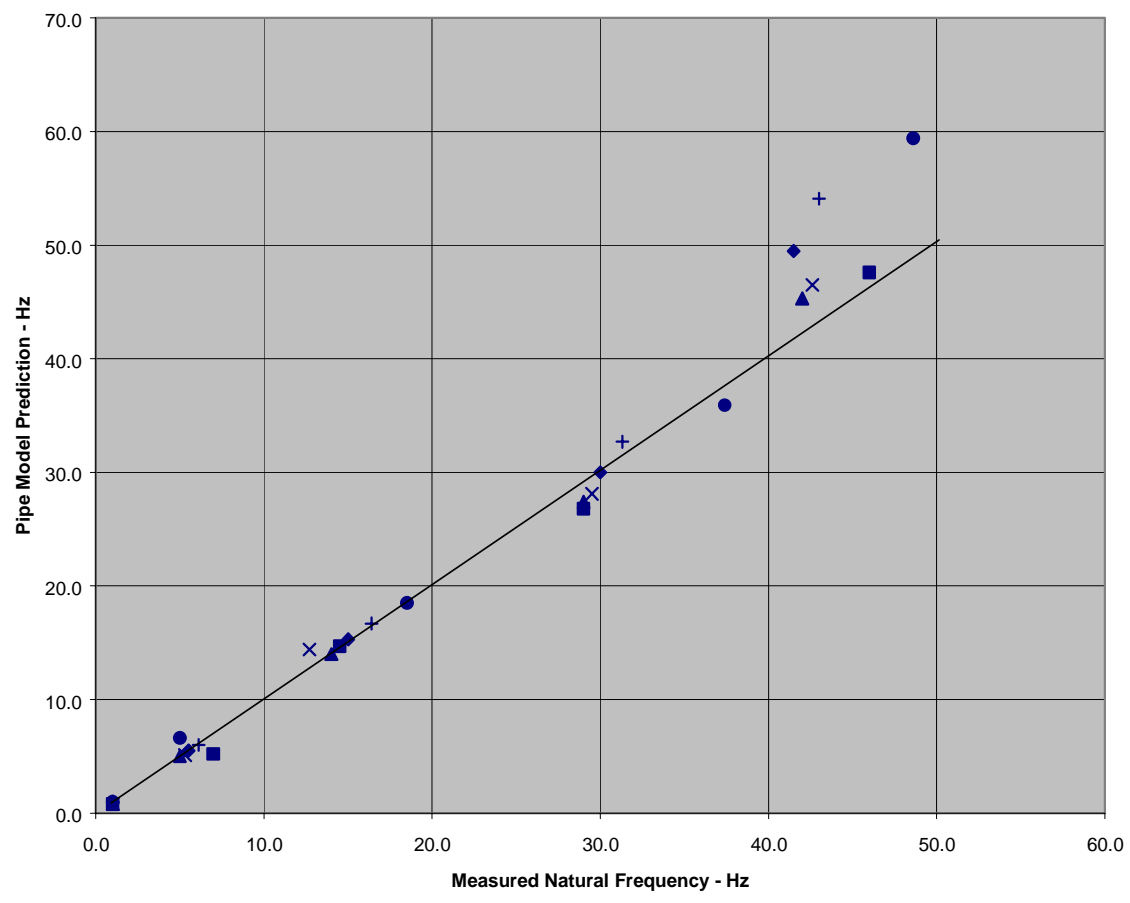

Figure 4. Pipe Model vs. Measured Natural Frequency 


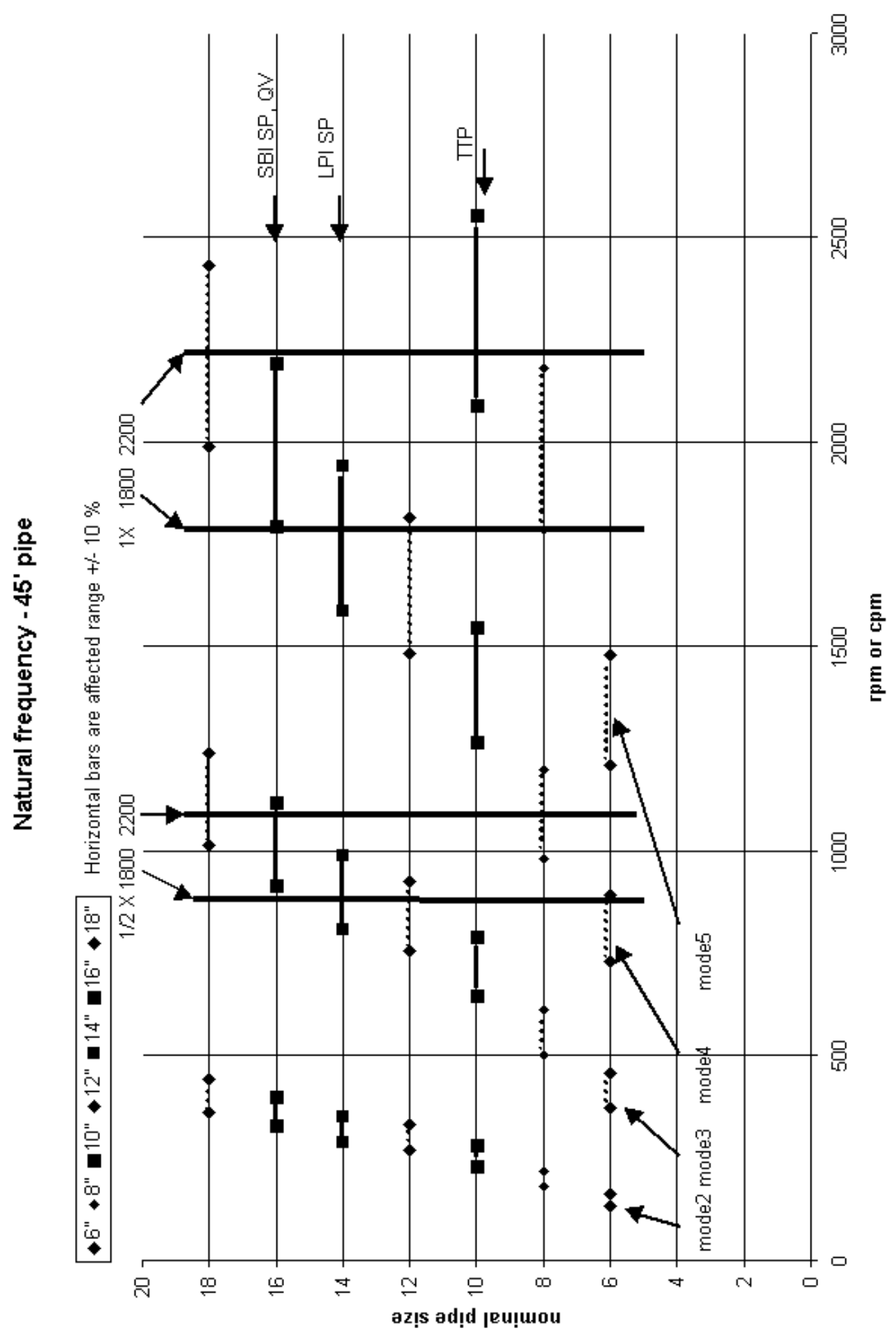

Figure 5. Natural Frequency - 45' Pipe 


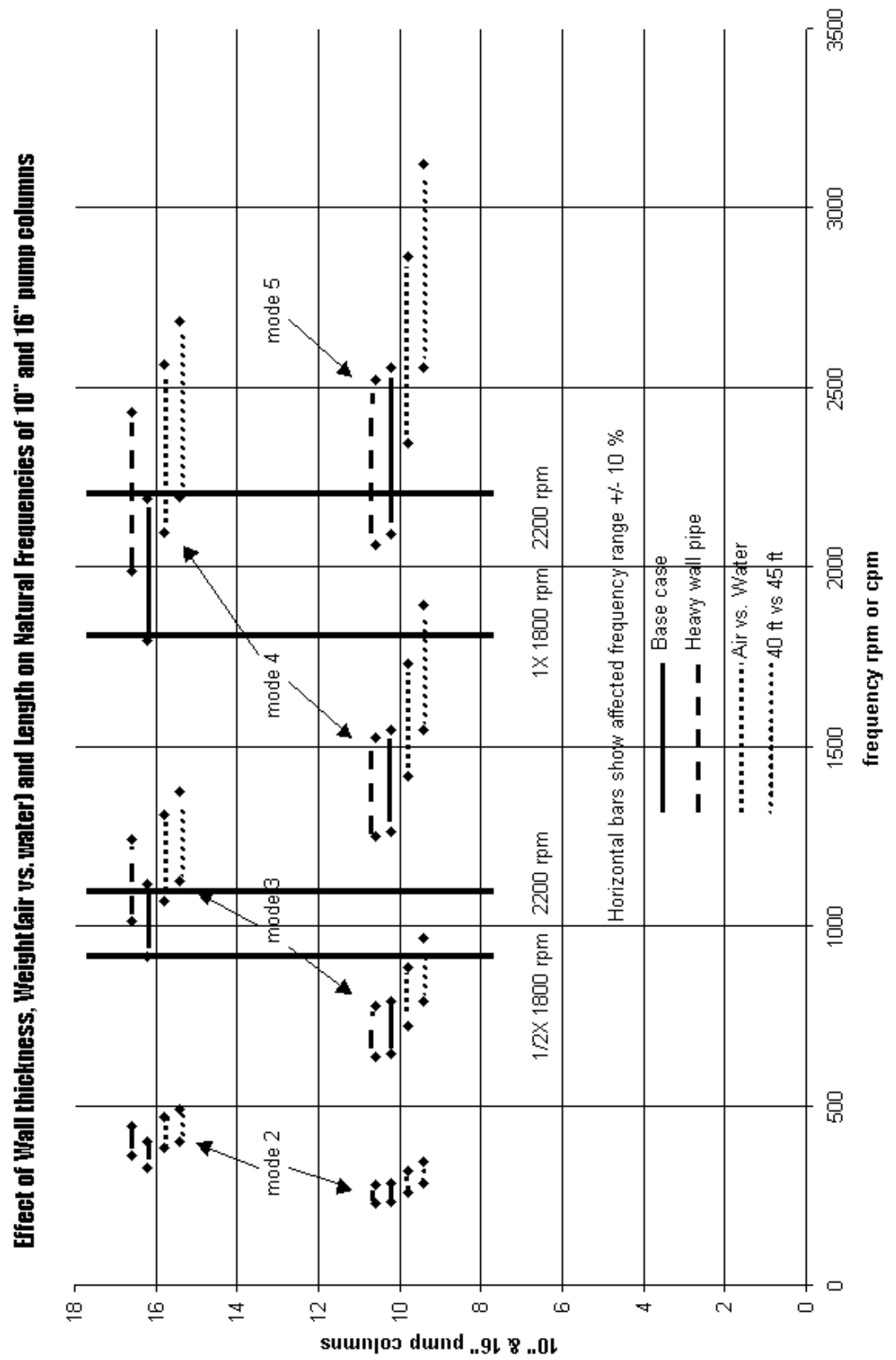

Figure 6. Effect of Variables on Natural Frequencies 
WSRC-TR-2001-00313

\subsection{ALIGNMENT}

The rotordynamic models indicate that the long-shaft pumps with journal bearings inherently have shaft instabilities and column natural frequencies. Some pumps seem to have acceptable, or at least low, column vibration. Franklin's study included cases to represent misalignment by varying bearing stiffness. His results showed that high shaft displacement just moves to different locations in the column. Corbo obtained similar results, but he did not attempt to model misalignment. Neither model truly represents a real physical pump because the number of possibilities for alignment variations is large.

The following is offered to provide insight into alignment variations. If any given bearing can have one of four angular locations and eight bearings are included, then at least 32 possible variations exist. Suppose having two adjacent bearings in the same angular location produces high vibration. The probability of this occurring is $1 / 4 \times 1 / 4=1 / 16$; with 8 tries $-8 \times$ $1 / 16=1 / 2$. Interestingly, four of eight Tank 8 pumps tested were accepted. All pump suppliers use tight machining tolerances to set column and bearing alignment. Bingham adds dowels. None provide for adjustment. None assemble in the vertical position. Provision for adjustment and vertical assembly might help with preload of journal bearings; measurement techniques would have to be developed. This issue may become a moot point if the bearing design is changed in the future.

\subsection{VIBRATION MEASUR EMENTS}

Modern vibration analysis has been essential to increasing our understanding of the causes and severity of long shaft pump problems. Even though minimal cavitation has been observed on some pumps, pump performance has never been an issue of hydraulic performance at SRS. The issue is reliability because repair is not possible after the pumps are installed. Modern vibration equipment came into use in 1993 through the High Level Waste Predictive Maintenance Group. It was used for a Telescoping Transfer Pump (TTP) run in and again in 1995 on the Tank 51 pumps. Knowledge and experience were lacking. After the shaft wear from unbalance was found in 1995, Bently-Nevada equipment and services were used to complete the program. A Bently Nevada ADRE system was bought and has been in use since. There is now an upgraded version with 16 channels. This system along with the Bently-Nevada 3300 monitor system - interlocked to variable frequency drives (VFD) - has made pump testing possible with a minimum of personnel.

The Predictive Maintenance equipment - Computational Systems, Incorporated (CSI) - has been continuously upgraded and is now comparable to the Bently-Nevada. Vibration Analysis is a non-destructive test under the auspices of the American Society for NonDestructive Testing (ASNT). As is usual with non-destructive testing (NDT), competent analysis requires training, experience, and judgment.

Vibration "standards" are widely misunderstood. A more appropriate term is "guidelines". Absolute numbers are nearly meaningless. Rather than an absolute limit, comparison and analysis provide the best insights into the integrity (future reliability) of equipment. 
The equipment being used today collects massive amounts of data. Data is stored based on pre-selected criteria or manually. The analyst has the option of displaying the data in about two dozen formats. Where appropriate, the software will analyze relationships between different data collection points on the pump. For example, motor vibration can be plotted against column vibration. We presently have 16 channels on the Bently-Nevada ADRE. A number of options are available using the hand-held CSI analyzer, but the collection and storage is manual - not continuous.

Two very useful displays are Cascade plots and Bode plots. Cascade is a display of multiple vibration spectra with frequency on the $\mathrm{x}$-axis and spectra arranged on the $\mathrm{y}$-axis as a function of speed. (Waterfall is similar but arranges spectra vs. time.) A spectrum may the half-spectrum (the familiar version in one direction) or full-spectrum. Full-spectrum is a calculated version pioneered by Bently-Nevada that separates the input from two orthogonal transducers to provide data which describes the ellipticity of the shaft's orbital path. It identifies severe rubs, drag, or high friction acting on the shaft. A half-spectrum cascade plot example is shown in Figure 7 with annotation.

Bode plots (and full-spectrum plots) require an optical trigger from the shaft. Bode plots show speed on the x-axis and two (or three) parameters on the $y$-axis. One parameter is phase angle; it is the angle of maximum vibration relative to the trigger location as the speed changes. When speed passes through a resonance point, the phase angle changes 180 degrees. The other parameter(s) on the y-axis can be total vibration and another choice usually the unbalance component. These two displays (cascade and Bode) contain most of the information needed to identify the existence and the probable cause of vibration problems. 


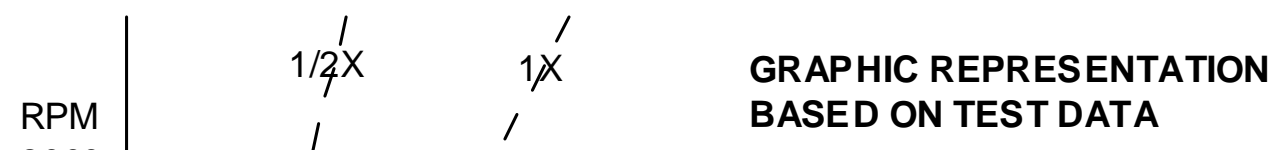

2000

1000

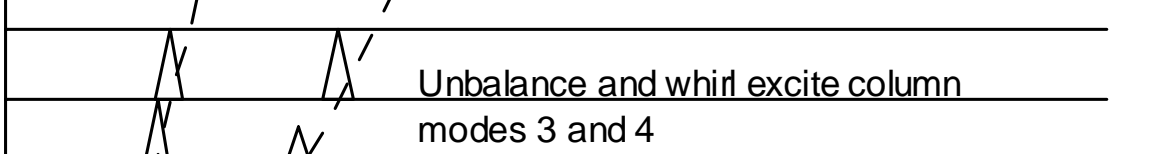

1

CASCADE PLOT FOR JOURNAL BEARINGS
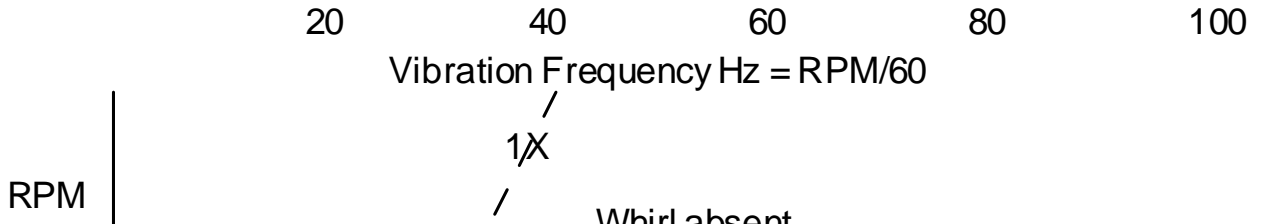

2000

1000
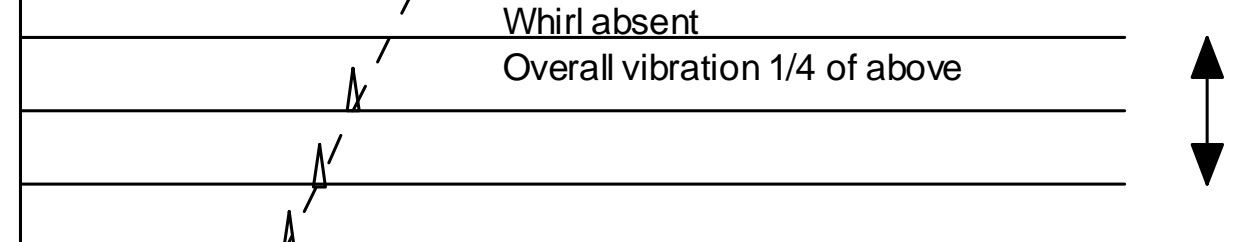

1000
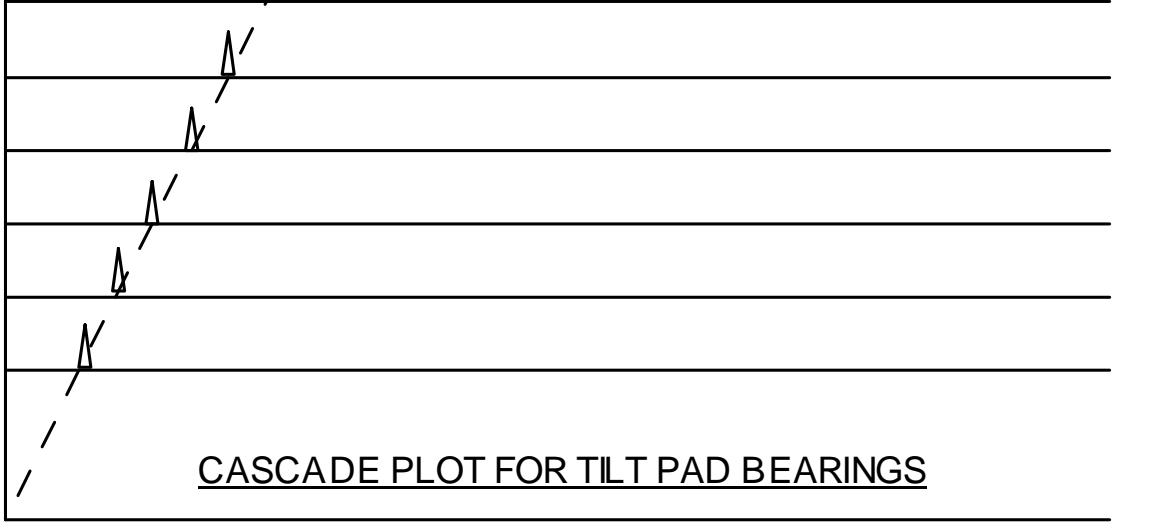

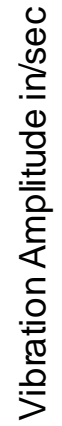

Figure 7. Cascade Plot Based on Test Data 
This page intentionally left blank.

Page 18 of 58 
WSRC-TR-2001-00313

\subsection{INDIVIDUAL PUMP PROGRAMS}

\subsection{ORIGINAL WASTE RE MOVAL PUMP DESCRIPTION}

The original waste removal mixer pumps were conceived in the late 1970s after a study that concluded that mixer pumps were preferred over agitators, sluicing, or any other means for suspending settled solids in waste tanks. The necessity to go down 40 feet through a riser, into tank diameters up to $85 \mathrm{ft}$., with some tanks filled with cooling pipes were overriding constraints in the technology choice.

The original supplier was Bingham-Willamette (later Sulzer Bingham, Inc.). The pumps were $45 \mathrm{ft}$. long, 16-inch water-filled pipe columns, 22-inch flanges, 2-inch shafting in four sections, and journal bearings every 58 inches. A $150 \mathrm{HP}$ motor is mounted on top. The pump end is at the bottom. Pump performance is $1200 \mathrm{gpm}$ through two horizontally opposed 1.5 inch diameter nozzles. The pump head is 190 feet of fluid. Hydraulic horsepower is about $58 \mathrm{HP}$ in water and $92 \mathrm{HP}$ in $1.6 \mathrm{sp}$. gr. fluid. Pump efficiency is about 70 per cent.

Bingham built over 60 such pumps. Sixteen pumps were converted later - twelve pumps to 4000 gpm pumps (Tanks 51, 49, and 40) and four pumps to recessed impeller pumps (Tank 48). Four unused pumps are on hand. Nearly 50 pumps have been used for waste removal mixing starting in the early 1980s. Two, three, or four pumps per tank were installed. Some few have not yet been used (e.g. Tank 41). The original pumps had V-ring seals at the bottom of the column and packing at the top. The design leakage was 1 to $2 \mathrm{gpm}$. Many SBI pumps were later fitted with mechanical seals, including all pumps currently in use.

\subsection{ORIGINAL PUMP PRO BLEMS}

Review of waste removal missions (early 1980s) showed that most of the pumps were deteriorating in use - usually apparent as seal leakage. The pumps had acceptable motor vibration in 24-hour pre-installation run ins at TNX. They were not inspected per se. Some bearing wear numbers are available from later extended tests on mechanical seals. At the time, the focus was on the mechanical seals and not on the shaft movement. The problems cited - excessive column water consumption and the bearing wear - are readily explained by shaft instability. Vibration measurement and rotordynamic analysis were primitive or nonexistent by today's standards. Thus, the root problem was unrecognized.

All documentation found on early pump use indicates that most if not all such pumps had increased leakage in use - with final leakage of 7 to $10 \mathrm{gpm}$. Time of use for these pumps was roughly 1000 hours to accomplish their waste removal missions. The increased leakage was unacceptable. In the worst case found, 775,000 gallons of water were added to one tank in order to remove a sludge and supernate mixture that was originally 300,000 gallons. The additional water is a large load on the tank farm evaporators. 
About the same time as the pump conversions mentioned above, in-tank processing of sludge and salt was being developed. Such water addition to a process was also unacceptable from a process standpoint. To reduce or eliminate the column water leakage, mechanical seals were developed. Years of testing and thousands of hours of running at TNX went into seal development. All the pumps still in use or installed and considered usable now have mechanical seals. At first, only the lower end of the column had a mechanical seal. The top retained the packing. The initial results from using these pumps in waste tanks are discussed in the next section because another problem occurred ${ }^{6}$.

Evidence also exists that the line shaft journal bearings had wear. At the time, the wear was considered acceptable (one case cited 12 mils). Bingham pumps running at $1780 \mathrm{rpm}$ do not have column critical speeds at running speed or at the shaft whirl speed. Their life is largely determined by shaft instability.

\subsection{TANK CONTAMINATI ON FROM ORIGINAL SEALS}

Extensive testing went into proving the reliability of mechanical seals. Total test time of 10,000 hours has been cited. One seal ran 1600 hours, was examined, then ran another 900 hours with no problems reported. The original lower mechanical seal was made by Durametallic (recently acquired by and changed to FloServe). A large number of pumps were retrofitted with the seals - more than 20 . In all cases, use of the pumps resulted in contamination of the pump top or tank top with no apparent seal failure. The cause of the contamination was proven to a reasonable degree.

Durametallic ran bench-top tests that showed pressure pulses nearly equal to column pressure (20 psig) caused by radial runout of 15 mils on the rotating seal face. This meant that radial runout caused backflow through the seal faces without a seal failure. The resulting contamination of the pump-column water escaped through the packing at the top of the columns - packing is required to leak for cooling and lubrication. Three corrective actions resulted:

- A top mechanical seal to replace packing

- Secondary containment on the pump

- A program to replace the Durametallic seal with one more resistant to shaft vibration

Such a seal was found made by Burgmann. The Burgmann seal faces were installed outside of the confined housing and a seal property called balance ratio was improved. In the 1980s, pump testing focused on mechanical seals, larger pumps for in-tank processing of sludge, and low-shear pumps for in-tank processing of salt solution. Studies were done on the effect of pump capacity on mixing. No evidence showed that the pump column or shaft stability was seen as an area for improvement.

When mechanical seals were put in service with packing at the top of the column, tank top contamination resulted from contamination entering the seal, although the seal had no physical failure. The problem was correctly diagnosed as excessive shaft movement affecting the seal. Nevertheless, the solution was seen as improved seals instead of reducing 
the shaft vibration. Lack of good rotordynamic analysis in the pump industry, the idea that shaft instability is inevitable and insoluble, and the lack of modern vibration analysis instruments all contributed to the perceived understanding of the problems at the time. From today's vantage point, a significant root cause was overlooked - excessive shaft runout or shaft instability ${ }^{6}$.

\subsection{HAZLETON PROTOTY PE FEED PUMP}

The Replacement High Level Waste Evaporator project (S-4062) purchased a Hazleton prototype long-shaft feed pump. The pump was similar to a Hazleton Telescoping Transfer Pump, but measured 35 feet long vs. 40 to 45 feet long. The hydraulic requirements were less - lower head and flow. The prototype feed pump was tested at TNX for 3000 hours until the lower seal failed. The seal was examined and failure was diagnosed as improper installation of a seal key. Difficulty installing the seal key had occurred previously. This may be the correct diagnosis. However, Hazleton pumps have similar shaft runout as other long-shaft pumps and the question arises if the seal failure (key not in slot or slipping out of slot) could have been aggravated by shaft vibration ${ }^{7}$.

\subsection{TANK 48 RUN INS}

Tank 48 pump run ins at TNX showed the shaft contacting the casing wear ring even though the diametric clearance was 0.018 inch (18 mils). An HLW/TNX program was initiated to counter the lower shaft runout with a prototype product lubricated bearing ${ }^{8}$. The primary concern was the effect of the runout on the lower mechanical seal. The Tank 48 pump shaft wear may have been caused by hydraulic unbalance.

Significant differences exist between Tank 48 and Tank 51 impellers and casings. Tank 48 impellers are simpler castings and the speed is much slower - 900 to $1200 \mathrm{rpm}$ vs. $2200 \mathrm{rpm}$. But the Tank 48 impeller is recessed, making it more sensitive to non-uniformity and it has a column critical speed close to $900 \mathrm{rpm}$. Continuing study of the Tank 48 pumps was supplanted by the work on Tank 51 pumps.

\subsection{TANK 51 RUN INS - TAN K 40 PUMPS (Hydraulic Unbalance and Vibration)}

Tank 51 pumps had failed lower mechanical seals after 700 to 1000 hours of use. The failures were found in the 1993 restart after initial use in 1988. Run in preparation for Tank 51 replacement pumps included disassembly before running; wear was evident after only 8 hours supplier testing - 10 years earlier. During running at TNX, severe shaft wear caused by hydraulic unbalance was revealed. Hydraulic unbalance was corrected with machined impellers 9 .

Diagnosis of the hydraulic unbalance was accompanied by diversions to other design details (larger shaft diameter and wear ring clearance) indicating some lack of understanding by all participants - SRS, supplier, and outside consultants. The program was a huge step forward 
nonetheless ${ }^{10}$. At the time of writing, the pumps are approaching 2000 hours run time (four years calendar time) in Tank 51 with no problems.

The SBI performance curve was included in the initial problem analysis of Tank 51 failed pumps. It is obvious that the pump is not operating at the Best Efficiency Point (BEP). Operating at the BEP is desirable because radial loads are minimized. The larger the pump the more important the guideline. In consultation with a former Bingham engineer, the nozzle size was increased from 3 inches to 3.62 inches. This resulted in the following changes $^{11} 12$ :

- The flow increased from $4000 \mathrm{gpm}$ to $5200 \mathrm{gpm}$.

- The head decreased from 145 feet to 120 feet.

- The power remained unchanged, verifying the analysis.

- The efficiency increased from 78 to 82 per cent.

- The UoD increased from 22 to $25 \mathrm{ft}^{2} / \mathrm{sec}$.

- The effective cleaning radius increased proportionately - thirteen per cent. (Sharpe 1994) (Sharpe and Poirier 1995)

\subsection{TANK 40 REPLACEME NT QUADVOLUTE SLURRY PUMPS (S-5580)}

Project S-5580 ordered five pumps for Tank 40 from Sulzer Bingham, Inc. of Portland, OR. The original Tank 40 pumps had been used for Tank 51 replacements (above). The S-5580 specification introduced 72 hours of supplier running with motor vibration and lower shaft proximity probe measurements, followed by disassembly and inspection. Prior specifications required eight hours supplier running, motor vibration measurement, and no inspection. Four failures occurred at the supplier. The old 8 hour specification requirement would have rejected none.

Supplier problems were partially analyzed (or partially communicated). The supplier test stand was a major part of the problem. It was analyzed and satisfactorily reinforced. Still, a later pump failed and a rotordynamic analysis was done on the pump itself. In response ,the line shaft bearings were modified - shortened from 4 inches to 2 inches, clearance reduced from 6 to 4 mils, and staggered bearing installation shims used. The bearing shims preload the bearings in a somewhat systematic manner. The supplier did not disclose all the rotordynamic analysis results nor all of their design rationale. The modifications were made to all five pumps including those previously accepted. Subsequent testing at the supplier met requirements. This experience introduced the importance of making vibration measurements on the column. Shaft instability is again the root cause problem.

Hydraulic performance testing was observed at SBI and an error was found. The initial performance test had flow through both the nozzles and a control valve. The correct head was not measured. SBI was requested to find the Best Efficiency Point and size the nozzles appropriately. This occurred prior to the vibration problems. Later SBI was threatened with loss of the order due to delays. The performance test was done again, but the head measurement is still questionable. SBI changed the nozzle diameter from 3 inches to 3.12 inches. The pumps were delivered to SRS in 1996 partially assembled. The pumps were 
assembled and were run in at TNX in 1998-1999 with no difficulty. The performance curve still did not identify the BEP. SRS changed the nozzle size from 3.12 inches to 3.62 inches the same as for Tank 51 - and for the same reason. The pumps are installed and use is just starting.

\subsection{TANK 49 PUMPS}

Four quadvolute slurry pumps were installed in Tank 49 in the 1980s and never run. Tank 49 had only a small amount of fluid and the waste activity was quite low - lower than any other tank. These pumps were certain to have hydraulic unbalance due to the method of making the impellers. In addition, the question of decontaminating and repairing pumps had been asked continuously for several years. There was no better opportunity or better reason to try decontamination than with the Tank 49 pumps.

In 1996, two pumps were removed (from the V-1 and V-2 risers). They were decontaminated at Barnwell to "clean" (less than $400 \mathrm{~d} / \mathrm{m}$ per $\mathrm{cm}^{2}$ maximum fixed contamination). The casings were sent to Oak Ridge because Barnwell facilities were inadequate. The pumps were reassembled at TNX with machined impellers, new shafts, new journal bearings, new seals, and 3.62 inch nozzles. They were run in with no difficulty and met the same standards as the S-5580 pumps. They were re-installed in Tank 49. The TNX pump effort was uneventful.

The significant part of this section is the evaluation of the decontamination effort that was done by SRS Operations and RadCon. The decontamination effort was difficult and costly. Parts had to be hand worked. Transportation was difficult and costly. The final evaluation was that the results did not justify the resources - money and exposure. The other two pumps in Tank 49 were left as is. The non-repaired pumps have restrictions on speed - with corresponding loss of performance - to prolong life. The re-worked pumps have no restrictions. Since Tank 49 waste activity was so low, consideration of working on a different tank's contaminated long-shaft pump is beyond consideration.

\subsection{WEST VALLEY / FLOW AY TESTING}

West Valley had 10 pumps similar to SRS waste removal pumps bought in the 1980s using SRS specifications. The supplier was Floway Pumps of Fresno, CA. All were leaking after about 1000 hours operation. West Valley ordered two replacement pumps. A 72-hour supplier run and inspection was introduced for the two replacement West Valley pumps. About 10 failures occurred before the two pumps were delivered. Two initial failures were due to faulty machining and quality control. The remaining failures were all related to shaft instability. This supplier's design practice included large (9 to 11 mils) bearing clearance.

SRS and Bently Nevada were called for consultation ${ }^{13}$. Large bearing clearance and shaft stability were the primary focus areas in the problem analysis. Two interesting events were part of this effort. Floway was very reluctant to decrease bearing clearances because they had used large clearances in thousands of vertical turbine pumps with no more than the usual 
industry problems. Vertical turbine pumps vary widely in design, particularly length to diameter ratio and they are usually multi-stage. This indicates that pumps must be analyzed on an individual basis i.e., individual design details.

The second event was a mid-program effort in which Floway assembled a pump with exceptional care. Runout was measured at every step to assure "perfect alignment." When tested, this pump had the highest vibration of all runs and bearings were destroyed in about one hour. Bently Nevada advanced the hypothesis that "perfect alignment" is not necessarily good. Some bearing preload is desirable. The testing and recovery occurred late 1997 and early 1998. The subsequent use of the pumps is unknown. The West Valley waste removal mission was practically complete at the time. Use, if any, would have been minimal.

\subsection{HAZLETON TTP PERF ORMANCE}

Hazleton Pumps, Inc. of Hazleton, PA, has supplied a large number of pumps to SRS for over thirty years. The company was named Barrett-Haentjens until 1994, but the pump name has been Hazleton. Their reputation is very good. Many Hazleton pumps are cantilever pump tank pumps. Hazleton has also supplied over 20 long-shaft transfer pumps for pumping waste from the large waste tanks. These pumps are called Telescoping Transfer Pumps or TTPs. The pumps have 10-inch water-filled pipe columns and are generally similar to mixer pumps with variations in the dimensions of design details. The telescoping feature is the discharge pipe. The pump column is a fixed length - either 45 or 40 feet. It is believed that no TTP has failed in service to date. Their reliability led to choosing a long -shaft pump for the Replacement High Level Waste Evaporator Feed Pump.

The flaw in assessing reliability of the TTP is that their service life requirement is low. A few hundred hours of operation will empty a waste tank. Two pumps in Tank 50 and Tank 51 for waste processing probably have yet to run 1000 hours. About four recent run ins with modern vibration measurements at multiple locations on the pump show that TTPs have similar column and rotor critical speeds to other long shaft pumps - not necessarily at the same speeds. The amount of shaft displacement is about the same - on the high side several mils. TTPs tend to have more vibration in shaft whirl than other pumps, but with no known problems. There is no obvious reason why TTPs should be any more reliable than other long-shaft pumps with journal bearings.

One design detail is of theoretical benefit. Hazleton installs the bearings with a loose fit and an anti-rotation pin. Other suppliers use a press fit. Hazleton's rationale is to provide a few mils of self alignment. The loose fit modifies fluid damping. Rotordynamic experts verify that bearing damping is essential to shaft stability. No thorough rotordynamic analysis has been done on a TTP. Their ultimate reliability is an open question. 


\subsection{LPI WASTE REMOVAL SLURRY PUMPS - PART I}

Thirteen Lawrence mixer pumps were delivered to SRS in 1996-97 for Waste Removal. The pump specification (about 1992) required 8 hours running at the supplier, motor vibration less than $0.2 \mathrm{in} / \mathrm{sec}$, and $5 \mathrm{mil}$ maximum dynamic runout at the lower end of the shaft. All pumps met the requirement at the supplier.

The first pump delivered was run 260 hours at TNX in October 1996 with continuous monitors on motor vibration and shaft proximity probes. Spot checks were made on column vibration. The pump was disassembled and inspected with measurements on bearings, shafts and seals. The run and inspection were very good.

In 1998, four pumps were to be run in for installation in Tank 8. During this effort, pumps that were fabricated alike and met the same specification were found not to perform alike with respect to vibration. By this time, researchers were aware that motor vibration and lower shaft runout were not the only measurements of importance. Most of the understanding came from the S-5580 and West Valley experiences. Column natural frequencies and column vibration were learned to be important.

Eight pumps were run in for Tank 8. (See Figure 8.) Four were accepted and four were rejected for high column vibration. Column vibration was not covered in the original specification. Tank 8 run ins were also subject to controversy and lack of agreement. Because of the Tank 51 experience, machined impellers were added to the specification first five pumps. The investment cast impellers that are the equal of machined parts were allowed - last eight pumps. No correlation in column vibration was found between machined and investment cast impellers. The four accepted pumps and the four rejected pumps fell in two distinct groups with respect to column vibration. The maximum column vibration was either less than $0.2 \mathrm{in} . / \mathrm{sec}$. or greater than $0.4 \mathrm{in} . / \mathrm{sec}$. Because of project urgency and the uncertain outcome of corrective actions, actions at TNX aimed directly at understanding or correcting the problems were set aside in favor of testing and finding acceptable pumps.

Five noteworthy events provide insight into the continuing understanding of long-shaft pumps.

1. Motor and top seal alignment - the usual and supplier recommended procedure for motor alignment is to align the motor to the upper end of the shaft. On the third pump tested, this could not be achieved. Detailed examination of tolerances and fit - and the knowledge that the supplier assembles the pumps in the horizontal position - revealed that the top seal can easily be off center which makes the shaft off center. The procedure was revised - with supplier concurrence - to center the motor, connect the pump shaft, and then loosen and let the top seal find the center. This changed one pump from being rejected to being accepted. It failed to work on three other pumps. It is the appropriate procedure for pumps with top seals containing ball bearings - as recent pumps are presently manufactured. 
Tank 8 LPI 91103

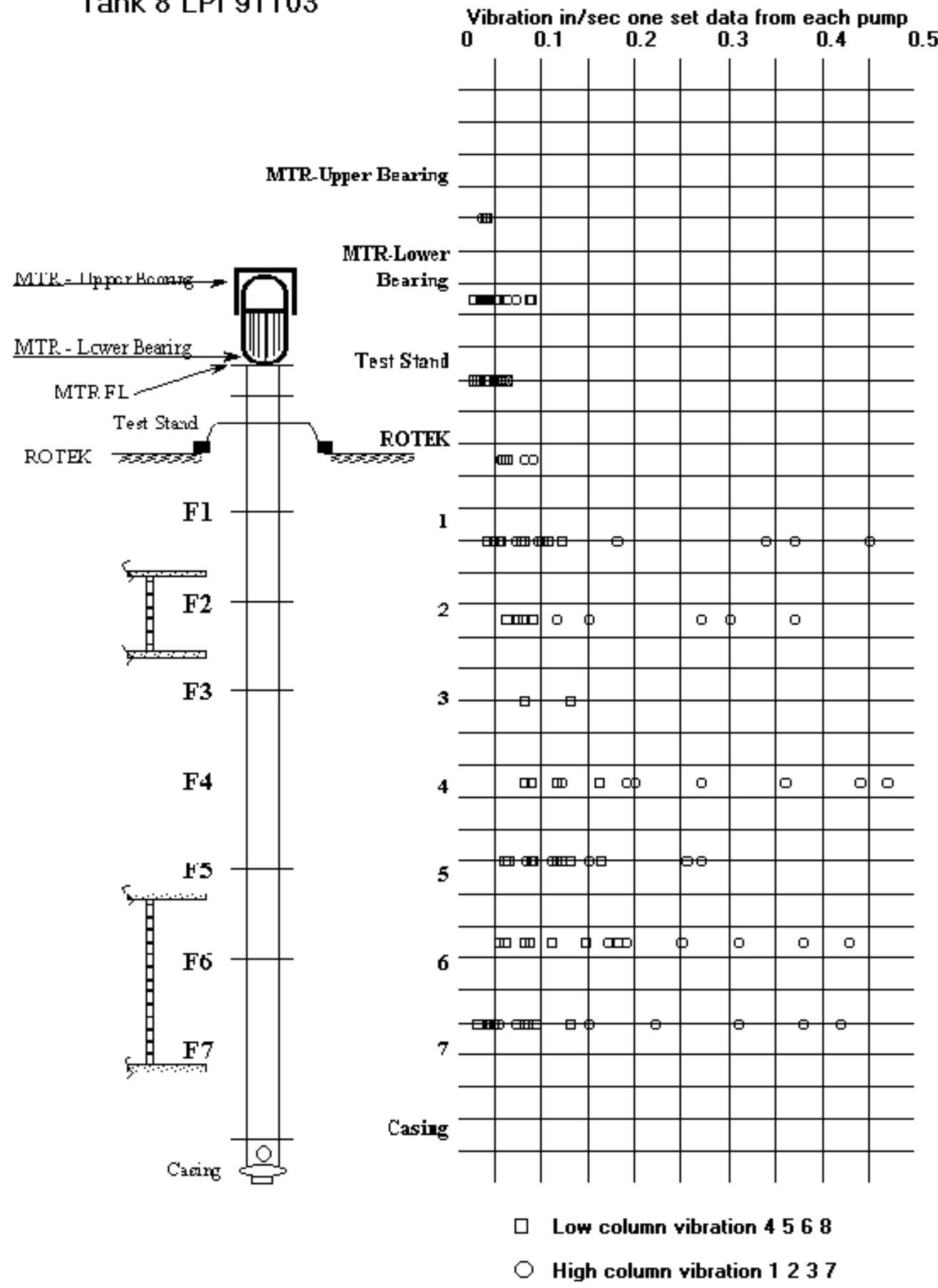

Figure 8. Tank 8 LPI91103 
2. Column resonance has been recognized but not defined almost from the initial use of long shaft pumps. Suppliers tend to view column resonance as inevitable, imprecisely predictable, and complicated to analyze. Supplier advice tends to be that pumps should not be operated at column natural frequencies and, if done, the pump life will be reduced. "Should not" and "reduced" are vague terms to the user or purchaser. Better terminology, used by rotordynamic experts, is "Pumps shall not be operated at critical speeds." Considerably lower risk is assumed by operating equipment at speeds other than critical.

The first Lawrence waste removal pump operated satisfactorily for 260 hours at a critical speed. Most of the other seven pumps which were run did not. Sulzer Bingham - S5580 and West Valley - Floway (above) had column-critical speeds or natural frequencies as factors in their problems. The Lawrence waste removal pumps, in particular, have column-natural frequencies at precisely the worst speeds - 900 and 1800 rpm. $900 \mathrm{rpm}$ is the whirl frequency and $1800 \mathrm{rpm}$ is the operating (unbalance) frequency. The excitation of these natural frequencies is variable, but for most of the pumps, the natural frequencies were excited. If not strongly excited in initial use, there is a high probability that minor bearing wear will result in excitation later.

Suppliers, and some rotordynamic experts, have viewed the calculation of columnnatural frequencies as complex and have not attempted a solution. Moreover, rotordynamic experts tend to view the entire pump as a system and only make a distinction between critical speeds that are "rotor dominated" and "column dominated." SRS/TNX has developed a simple pipe model - fixed at one end - that accurately predicts the measured natural frequencies of all pumps tested to date. They are two Sulzer Bingham models, one Hazleton model, two Lawrence models, and the Advanced Design Mixer Pump. Column diameters are 10", 14" and 16". Lengths are 35', 40' and 45'. Weight varies from 5000 to $20,000 \mathrm{lbs}$. The only difference from calculating a piece of pipe is that the actual suspended weight is used. It is a useful tool.

The identification of shaft whirl and a growing understanding of its significance, led to the recommendation that Lawrence waste removal pumps not be operated at the design speed of $1780 \mathrm{rpm}$. The project has installed Variable Frequency Drives for operation at $1600 \mathrm{rpm}, 10$ per cent from one of the critical speeds. Attempts were made to see if the pumps could be operated 10 per cent above the critical speed or $2000 \mathrm{rpm}$. They could not be. The unbalance component of the vibration decreased after passing through the critical, but rotor instabilities drove the total vibration higher. The pumps may have the possibility of operating at $2000 \mathrm{rpm}$ if the rotor problems (bearing design) are resolved. 
3. After seven pumps had been run in or tested, an exhaustive analysis of vibration data was performed to compare against acceptance or rejection, which is the same as low or high column vibration. The only other vibration parameter - meaning not column vibration - that correlated was the magnitude of the $1 / 2 \mathrm{X}$ component of the shaft proximity probes which measure the shart vibration at the bottom of the pump. The $1 / 2 \mathrm{X}$ magnitude is a measure of the shaft instability. If the $1 / 2 \mathrm{X}$ component was high roughly more than 0.2 mils - then the column vibration was high. The magnitude of the $1 / 2 \mathrm{X}$ component varied from less than 0.2 to nearly 3 mils for the seven pumps analyzed.

4. After three pumps had been accepted and the goal of accepting four pumps seemed achievable, one pump with high column vibration was allowed to continue running. The previous pumps rejected were shut down promptly after data was taken to avoid damaging the expensive shafts and, secondarily, the bearings. Prompt meant one to three hours. The pump that continued running showed evidence of deterioration in about 24 hours. By 66 hours, the evidence of damage was overwhelming and the run stopped. The column water drained from the pump was black with particles from bearing wear. The shafts were later found worn. The vibrational evidence is the ratio of the whirl frequency to the running frequency. Textbook references to whirl cite a frequency of 0.42 to $0.48 \mathrm{X}$ running frequency as the normal whirl frequency. This probably refers to horizontal shaft pumps. The normal starting whirl frequency seen on SRS long-shaft vertical pumps is $0.49 \mathrm{X}$. When bearing wear occurs, the whirl frequency steadily decreases as wear proceeds to as low as $0.3 \mathrm{X}$. This has been observed at Sulzer Bingham, Floway, and here in this instance. The ratio at 66 hours was $0.33 \mathrm{X}$.

5. Consultants were called in to help with the resolution of the problems. SRS pump history, the immediate testing history, and the project constraints were reviewed. Two significant results were achieved. The rejection of pumps with high column vibration was confirmed to be appropriate. The issue of shaft stability and the inevitable instability with journal bearings was raised. Tilt pad bearings and some other bearing variations were mentioned. The question of predictable reliability with journal bearings was raised in a low key manner. Wholesale changeout of bearings was not, however, a viable project option at the time. There was not universal agreement on the questions about journal bearings. Suppliers and persons with vertical turbine pump experience felt they were acceptable. Rotordynamic experts were the primary questioners. Thorough rotordynamic analysis was recommended. As with bearing changeout, this action did not fit within the project scope at the time. It has since been done. (See Rotordynamics section above.)

\subsection{EVAPORATOR FEED PUMP}

A separate report has been written on the $3 \mathrm{H} \mathrm{EFP}^{14}$. An abbreviated report is included here for completeness. Shaft instability is a factor in the lengthy preparation this pump received. This paragraph is the summary, results and conclusions from the longer report. 
A long-shaft pump with water-filled column was tested at TNX for the $3 \mathrm{H}$ Replacement High Level Waste Evaporator - Project S-4062. The test plan called for a 1000-hour run; disassembly, inspection, and re-assembly; and a 72-hour pre-installation run. The task (planned to take three months) ended up taking a year. Five significant problems were found and corrected:

- piping leaks

- defective shaft coating

- overly large product lubricated bearing clearance

- alignment errors or changes

- inadequately-cooled lower seal design

The long-shaft feed pump concept has inherent problems including shaft instability and column natural frequencies.

The primary problem is the line shaft bearings (journal bearings). There appears to be a solution in hand with tilt pad radial bearings. There was insufficient time to use this development. The pump put in service was installed in the best condition possible with the resources, time and money, provided. It has a chance of running 8000 or more hours. The importance of testing at TNX was reconfirmed. The importance of specifying good rotordynamic analysis has been learned. The assessment of the pump as being unpredictable is a concern - the solution is the prompt procurement of a spare.

\subsection{ADVANCED DESIGN M IXER PUMP PROTOTYPE}

The Advanced Design Mixer Pump (ADMP) program was conceived by Hanford as a joint effort between Hanford and SRS. Dale Waters was the lead engineer and did the majority of the work for the first two years. The team included three from Hanford and two from SRS. Hanford did the procurement and SRS did the testing. All five team members participated in all decisions. Original members were Waters, Steve Riesenweber, Craig Shaw, Mike Dalmaso, and Charley Sharpe. Hanford leads have been Waters, Mark Hall, Darryl Lamberd, and now Craig Shaw. The Table 3 summarizes the key events from 1993 to present.

The specification is described as performance based. No significant design details were specified $^{15}$. An independent reviewer ${ }^{16}$ criticized the specification for this omission when it was in fact part of the intent. Risers sizes (Hanford and SRS), mounting structure, tank sizes, mixing requirements based on $\mathrm{UoD}$, number of pumps per tank, and auxiliary requirements such as available electrical power and water, or its absence, were given. A table was prepared to evaluate the conformance of the proposals to the conditions in the preceding sentence with a predetermined weighting factor. The absence of column water and not exceeding $350 \mathrm{HP}$ are two examples of conditions given heavy weight. 
Table 3. Key Events for ADMP Program

DATE EVENT

3/7/93 Initial discussions Hanford and SRS at Houston Pump Symposium

6/15/93 WHC/WSRC joint program agreement

11/29/93 Issue specification WHC-S-0211

1/4/94 Request for Proposals out to 30 vendors, 7 replied, 3 evaluated seriously

6/7/94 Proposal evaluation complete; negotiations initiated

10/25/94 Best and Final Offers received

12/12/94 Selection Committee recommendations completed; fund two designs WEMD and LPI

9/15/95 Final Design Review of WEMD and LPI; funding for only one pump; LPI selected

9/30/95 time est; LPI prototype ordered

4/24/97 LPI start up test

7/23/97 Last of 5 Sealol seal failures; change to Flexibox

4/29/98 ADMP start up at TNX in position 5; column vibration high; test speed $950 \mathrm{rpm}$

12/31/98 time est, complete $2000 \mathrm{hrs}$ in water - 1st goal

$1 / 15 / 00 \quad$ time est, $4000 \mathrm{hrs}$ in water - 2nd goal

4/15/00 time est, kaolin unloaded with ADMP, start 100 hrs., indications of bearings fail

9/15/00 time est, bearing failure, repair unavoidable

11/15/00 repair in progress, replace one bearing, cage broken

12/31/00 Deadline; complete 500 hour kaolin run, dump kaolin. Overhaul pump if funded

A bidder's conference was held at Hanford. Seven replies were received to the Request for Proposals. One was one page, two were judged not to have adequate design or fabrication ability; one was water-filled; the remaining three were given serious consideration and the three were ranked as follows:

1. Westinghouse Electromechanical Division (WEMD) - A submersible pump with product lubricated bearings

2. Rockwell International and Borg Warner International Products - was Byron Jackson (RI/BW) - A submersible pump with magnetic bearings and mechanical seals

3. Lawrence Pumps, Inc. (LPI) - A gas filled column with oil lubricated bearings, otherwise similar to existing pumps 
Two designs were purchased - WEMD and LPI. The designs are DOE property. After Final Design review, one pump was purchased - LPI. WEMD was ranked highest in the proposal stage. In the design stage, the WEMD design became more complex, there were bearing test problems, and cost was high ${ }^{17}$. LPI received the order for the prototype.

In the procurement and fabrication stage, LPI had problems with Sealol gas seals - five failures. LPI changed to Flexibox seals - no failures. The Sealol seals are aerodynamic rotation lifts and separates the seal faces. Aerodynamic has the advantage of not using gas when not running; it has the disadvantage of the faces contacting during start up until sufficient lift is developed. Flexibox seals are aerostatic - column pressure separates the seal faces. Aerostatic has the advantage of starting on a gas film; it has the disadvantage of using gas - running or stopped. The gas pressure can be reduced for long shutdowns.

The LPI prototype ADMP was started up at TNX Full Tank in April 1997. A Reliance Variable Frequency Drive (VFD) came with the pump. The pump is 55 feet long, (shortened to 45 feet for TNX), 16 inch column, 42 inch diameter casing, $300 \mathrm{HP}, 1200 \mathrm{rpm}$ motor. Each five-foot section is individually removable (a Hanford desire) and has one thrust bearing, one radial bearing, and one splined shaft. The minimum speed is $650 \mathrm{rpm}$ due to internal oil pumps for the ball bearings. Full weight including turntable and motor is 20,000 lbs. Performance is 10,500 gpm at $1185 \mathrm{rpm}, 52$ feet of head, 18-inch mixed flow impeller, and two 6-inch nozzles. UoD is about $29 \mathrm{ft}^{2} / \mathrm{sec}$. Theoretical cleaning radius is over 50 feet.

High vibration at full speed became apparent at startup. An indication of a peak in vibration occurred at $1100 \mathrm{rpm}$. Charles McKeel of System Engineering - Structural did a thorough analysis of the Full Tank structure and the pump ${ }^{18}$. He concluded the problem was in the pump. At 45 feet length, there is a column natural frequency at $1100 \mathrm{rpm}$. This was verified with impact tests. The vast majority of ADMP testing has been at 700 to $950 \mathrm{rpm}$. The pump column was braced with turnbuckles to allow testing at full speed, but the turntable cannot be used when braced. Theoretically, the configuration of the pump at 55 feet length will have a lower natural frequency. $1185 \mathrm{rpm}$ may be sufficiently above the natural frequency to allow safe operation at design speed. The tests with bracing were intended to support this argument and they do.

The pump has run over 4000 hours in water. Because of other testing in the Full Tank, the running has been on an opportunistic basis, i.e. when another pump was not being tested. Kaolin was loaded into the Full Tank in April 2000 for a 500-hour kaolin demonstration. The pump ran 100 hours and a lower thrust bearing failed. 4000 hours is less than normal ball bearing life. To this point, the pump has been started and stopped at least 100 times. The VFD has had no problems. The pump is presently being repaired for continuation of the 500-hour run. A December 31, 2000, deadline is associated with the run because of environmental restrictions on dumping the kaolin (SC DHEC). 
An assessment of the ADMP is in order although the testing is incomplete and the inspection and overhaul have not been done. It is a qualified success. It has ample cleaning radius based on a spot check and theory (even at $950 \mathrm{rpm}$ ). It ran 4000 hours - longer than any other long shaft pump known. Most pumps to date have a life of about 1000 hours. The Tank 51 replacement pumps may be approaching 2000 hours. 4000 hours is not a statistically sound number, but it is the only number.

Some suggestions for improvement follow. The column resonance near the design speed should be avoided. The design is complicated - simpler shafts, couplings and bearings (sealed grease) can probably be designed. (The current design was influenced by the language in the specification). A product lubricated bearing is needed. Impeller uniformity should be improved. Nozzle design can probably be improved. A more simple lower seal or maybe no seal at all should be investigated. (In three years, there has been no failure of the TNX gas supply). For SRS, the smaller diameter version is required and, in some tanks, the high flow is expected to damage cooling coils.

The preceding paragraph was an assessment of the prototype ADMP. Another assessment should be performed, not necessarily by the authors of this report. The concept behind the ADMP should be evaluated. This was alluded to when the specification was described as performance based. The idea was that the mixing performance and the physical constraints would be specified, but Hanford and SRS would not specify design details. In this way, the resulting offerings would be the best that the pump industry had to offer. Whether this happened is questionable. Whether we know our requirements is an open question. For example, WEMD was given a sludge simulant formula to use for bearing tests that was excessively demanding; it was later relaxed by a factor of 100 to 1000 per cent. WEMD made significant design changes based on the original requirement. A second example, LPI made a pump with a natural frequency that restricted speed. (This last comment is based on lessons learned later). Cost had a relatively low weight in the original evaluations, but later became an important factor in the prototype purchase. Is the prototype the best that the industry has to offer? Would it be better to take all lessons learned on vibration, materials, expected life, and mixing and, in effect, come very close to specifying the design? Having a pump manufacturer involved would improve the results, but the practicality, under government rules, is questionable. This paragraph is intended to bring all of these questions under discussion.

\subsection{LPI WASTE REMOVAL SLURRY PUMPS - PART II}

After the Tank 8 mixer pump run ins in 1998, it was obvious that the remaining nine pumps could not be handled in the same manner. Four of the remaining nine had been tested and rejected. Five had not yet been tested. Observations were made during the Tank 8 effort and technical lessons were learned working on the Replacement High Level Waste Evaporator Feed Pump. The path forward for the LPI Waste Removal mixer pumps was easy to define. 
At the top of the list was testing tilt pad bearings. The shaft coating will be replaced to avoid a repeat of the Tank 8 stuck shaft problem. The solution to the shaft coating is a sleeve. At the same time, the clearance on the product lubricated bearing will be more carefully controlled by replacing the silicon carbide bearing. The coupling split retainers were the same design as the EFP. Replacements were designed with less play. The product lubricated bearing clearance and the split retainers are probably of small importance compared to new shaft bearings, but they are inexpensive modifications in a helpful direction.

The last potential change is more difficult to assess. The impellers are very uniform. The casings are sand castings and are not uniform. Side-to-side variations up to 0.2 inches were found. These explain the $5 \mathrm{X}$ running speed vibration frequencies found in all pumps tested. The amount of $5 \mathrm{X}$ vibration varied from pump to pump; in one pump, it was the largest peak in the shaft displacement. Repairing the sand cast casings would seem to involve welding and grinding. Such activities could damage the casings beyond use. Replacements would be costly. At the same time, the effect of the $5 \mathrm{X}$ vibration is difficult to assess. New bearings may accommodate this vibration in an acceptable manner. To date, nothing has been done about casing non-uniformity.

Another action in the recovery plan was the two rotordynamic analyses discussed in a previous section. A second part of Mark Corbo's task was designing the tilt pad bearings. This was done in parallel with analysis. The bearings were ordered and received. They have been tested in one pump with excellent results. Shaft whirl has been eliminated. Total vibration was low - less than $0.1 \mathrm{in}$./sec vibration velocity anywhere. The column natural frequencies have not changed. With the tilt pad bearings, operation above the $1800 \mathrm{rpm}$ frequency may be possible. Inspection of the bearings after 288 hours of operation shows only minor scratches due to particles in the water. This is a brief report on the latest activity. A more detailed report should be issued separately. 
This page intentionally left blank. 


\subsection{CONCLUSIONS}

The outlook for satisfactory designs of long shaft pumps has improved with the recognition of the problem causes. Tilt pad bearings are very promising as part of the solution. Prior knowledge of column natural frequencies (in the design phase) is the other part of the solution. Water-filled, long-shaft pumps may prove to be the most cost-effective pump design if current developments fulfil their promise. Opportunities exist to reduce the cost of design and fabrication. At least two alternative pump configurations - air-filled columns and submerged motor - can be tried. 
This page intentionally left blank.

Page 36 of 58 


\subsection{RECOMMENDATIO NS}

The water-filled, long-shaft pump may be the most cost effective pump for the future. Recommendations for such a pump include the following:

1 Continue to develop tilt pad bearings.

2 Perform rotordynamic analysis in the design stage using Mark Corbo's methods. (See Rotordynamics section for explanation.)

3 Use machined (or investment cast) impellers and casings.

$4 \quad$ Know the column natural frequencies in the design phase.

$5 \quad$ Evaluate seals for adequate cooling.

6 Evaluate nozzles for improved external hydraulic performance.

7 Maintain supplier relationships and contacts.

8 Simplify specifications, do not expect suppliers to solve all problems and do not include vague requirements that cannot be measured.

9 Increase the amount of liaison between SRS subject matter experts and suppliers during procurements.

10 Perform rotordynamic analysis on unanalyzed existing pumps and monitor their field performance (quadvolute, old waste removal, TTP and 3H EFP).

11 Continue to make use of the latest vibration measurement and analysis capability.

12 Pay special attention to motor-to-top seal alignment procedure. (See section 4.11.) 
This page intentionally left blank.

Page 38 of 58 


\subsection{FUTURE WORK}

Submerged motor pumps or mixers are definitely an option. Hanford has a "success" in the Hazleton SY-101 pump. It has 1194 starts but it has problems with cooling and it has not run 1000 hours. A similar pump failed in another Hanford tank; this was not publicized. A second option is gas-filled ball bearing long shaft pumps. They are unknown in industry. The one test to date is reasonably successful. The ADMP ran 4000 hours. The ADMP had problems with column natural frequencies and ball bearings have no damping. Rotordynamic experts say damping is needed. The Hazleton journal bearing design is unique in having some (unknown) damping. No Hazleton long-shaft pump has failed, but none have yet run 1000 hours. Decisions on alternatives are a future task.

The following should be investigated as opportunities for reduced cost pumps:

1 Simplify column design and fastening; evaluate screwed column couplings and smaller columns.

2 Eliminate column gaskets - use flat, grooved faces and a sealant.

3 Use screwed couplings - pin to prevent unscrewing.

4 After supplier testing and inspection, ship pumps to SRS disassembled - there are multiple advantages, e.g., SRS inspection and measurement, SRS familiarization, no shipping cradle, identification of shipping damage. Assemble at SRS with supplier supervision.

5 Find a satisfactory column, bearing, and shaft design and standardize it. For example, 8 " heavy wall pipe may be equal to 16 " standard wall pipe and simplify fabrication and assembly. All the column has to do is hold the bearings. The volume of water is 100 gallons instead of 400 gallons. (See Figure 5 and Figure 6.)

6 Qualify two preferred suppliers and use both.

7 On gas-filled columns, seek a method to damp bearings; simplify seals - expensive lower seals may be unnecessary. 
This page intentionally left blank.

Page 40 of 58 


\subsection{APPENDIX A}

\section{DESCRIPTION OF PIPE MODEL FOR PUMP COLUMN NATURAL FREQUENCIES}

Charles McKeel constructed this model at HLW request.

Pump Column Vibrations

The natural frequency of a cantilevered pipe beam is a function of length $\boldsymbol{l}$, moment of inertia $\mathrm{I}$, modulus of elasticity $\mathrm{E}$ (a material property), and mass per unit length $\mathrm{m} . \mathrm{m}=\mathrm{W} / \mathrm{lg}$ where $\mathrm{g}$ is $386.4 \mathrm{in} / \mathrm{sec}^{2}$. The first five modes are:

$f_{i}=\left(B_{i}^{2} / 2 \pi\right)[E I / m]^{0.5}$ and the first five roots are:

$\mathrm{B}_{1} l=1.8751$

$\mathrm{B}_{2} \boldsymbol{l}=4.6941$

$\mathrm{B}_{3} l=7.8548$

$\mathrm{B}_{4} \boldsymbol{l}=10.996$

$\mathrm{B}_{5} \boldsymbol{l}=14.137$

Moment of inertia $\mathrm{I}=(\pi / 64)\left(\mathrm{D}_{\mathrm{o}}{ }^{4}-\mathrm{D}_{\mathrm{i}}{ }^{4}\right)$ and for a solid section let $\mathrm{D}_{\mathrm{i}}=0$ or let $\mathrm{t}$ below $=0.5 \mathrm{D}_{\mathrm{o}}$

Thus $\mathrm{f}_{\mathrm{i}}=3687.4\left[\left(\mathrm{~B}_{\mathrm{i}} l\right)^{2} / l\right]^{2}\left[\left(\mathrm{D}_{\mathrm{o}}{ }^{4}-\mathrm{D}_{\mathrm{i}}{ }^{4}\right) l / \mathrm{W}\right]^{0.5}$

$\mathrm{W}$ is pounds

$\mathrm{D}$ is inches

1 is inches

$\mathrm{t}$ is inches (wall thickness)

An EXCEL spreadsheet for the above is available from HLW/TNX. 
This page intentionally left blank.

Page 42 of 58 
WSRC-TR-2001-00313

\subsection{APPENDIX B \\ MEMORANDUM ON ESTIMATING SIZE AND HORSEPOWER OF MIXER PUMPS}

\section{MEMORANDUM}

\section{MIXER PUMP SCOPING}

SRT-LWP-2000-00171

C. L. Sharpe 11-6-00

\section{$\underline{\text { Summary }}$}

A spreadsheet and two figures have been created to aid in evaluating concepts for new mixer pumps. When compared against the data in hand, the fit is quite good. Any individual calculation is probably $+/-10$ per cent or better.

\section{$\underline{\text { Purpose }}$}

The immediate purpose of this document is to serve as an aid to the group working on Tank 18 mixing alternatives. In the event that a mixer is being considered that is not yet in existence, these calculations can provide an estimate of the cleaning radius, horsepower, and size. The limitations of different pumps can be graphically seen in the first figure. More details are supplied in the EXCEL spreadsheet accompanying this WORD document. Two figures and two tables have been made part of this document.

\section{Examples of Use}

Suppose an ECR of $50 \mathrm{ft}$. Multiple pump designs will provide this. But the smallest nozzle for $50 \mathrm{ft}$. ECR is 4". At this point the BHP is about $200 \mathrm{hp}$, the rpm is 1750, and the flow is $3300 \mathrm{gpm}$ for one nozzle. (If the pump is two nozzles double the flow and the horsepower). The impeller diameter is about 18 ". Head is roughly $150 \mathrm{ft}$. (from table or spreadsheet). The specific speed Ns (see Appendix) is 2350. The second figure shows this is a Francis vane type impeller and the casing diam. might be around 1.4 times the impeller diam. or 25 in. With design tweaking, such a pump could probably be reduced in diam to fit down a $24 \mathrm{in}$. riser. Note: this describes a pump similar to the quadvolute with about 60 percent more flow per nozzle.

Second example for $50 \mathrm{ft}$. ECR at far right of graph. 14" nozzle, 12" impeller, $850 \mathrm{rpm}, 100 \mathrm{BHP}$, and 11,500 gpm for one nozzle. With a 14" nozzle and 12" impeller, such a pump is easily into the high specific speed category, meaning the flow is axial and the impeller is a propeller. The casing and nozzle are essentially a tube. 14" will fit through a 24" riser but the support system and power transmission are undefined. In essence this describes a smaller, higher speed Flygt mixer. One option is to insert and then rotate the same as the Flygt mixer. This is the same performance the Flygt mixer promised, but could not deliver because of poor structural and hydraulic design details.

In between the two examples, there are others. Watch the relationship between impeller size and nozzle size; some options on the graph are physically unfeasible.

Real data (see graph): L=LPI, S=Std SP, Q=quadvolute, A=ADMP, F=Flygt. All are in excellent agreement even though designs vary considerably. 


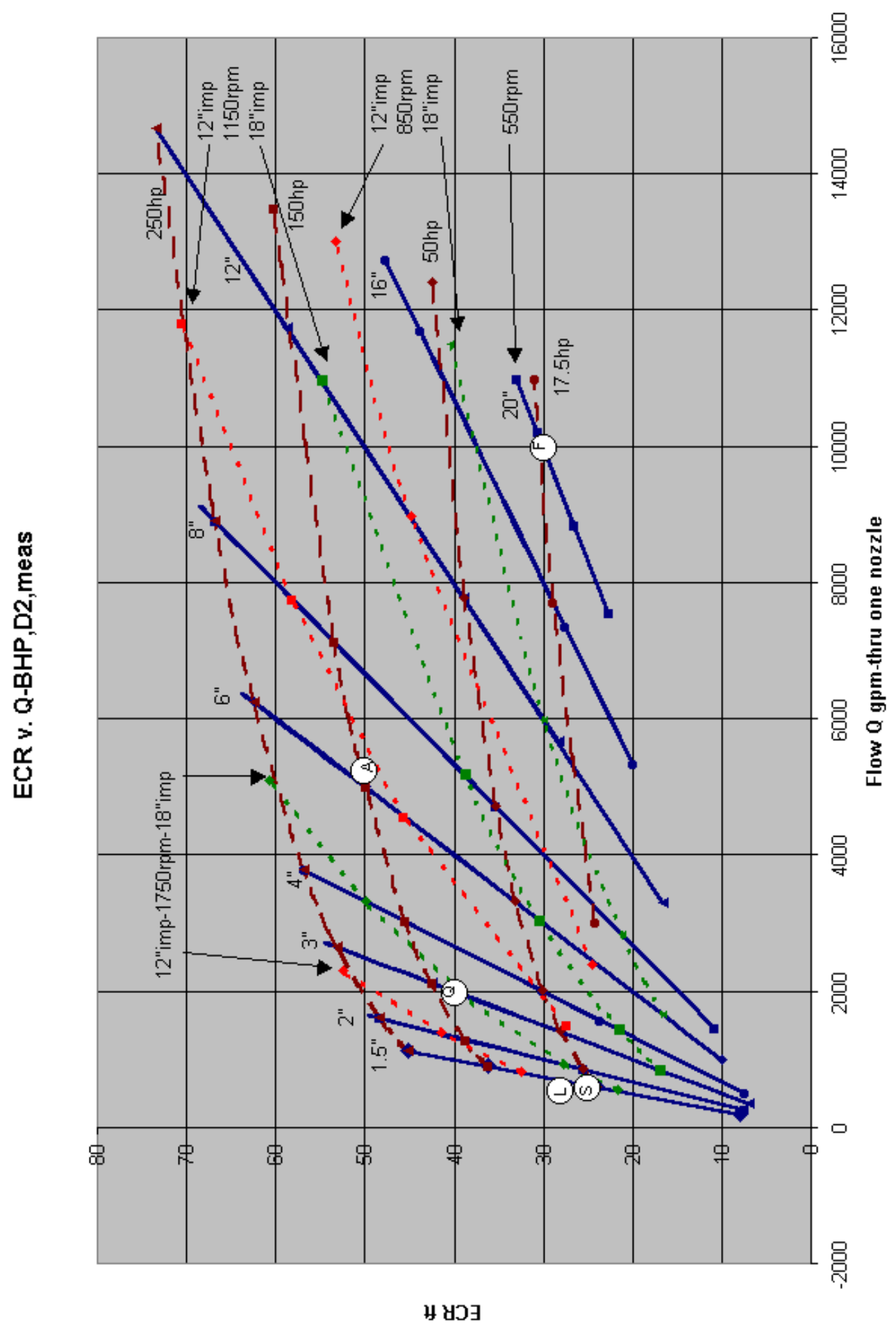

Figure 9. ECR vs. Q-BHP, D2, Meas 


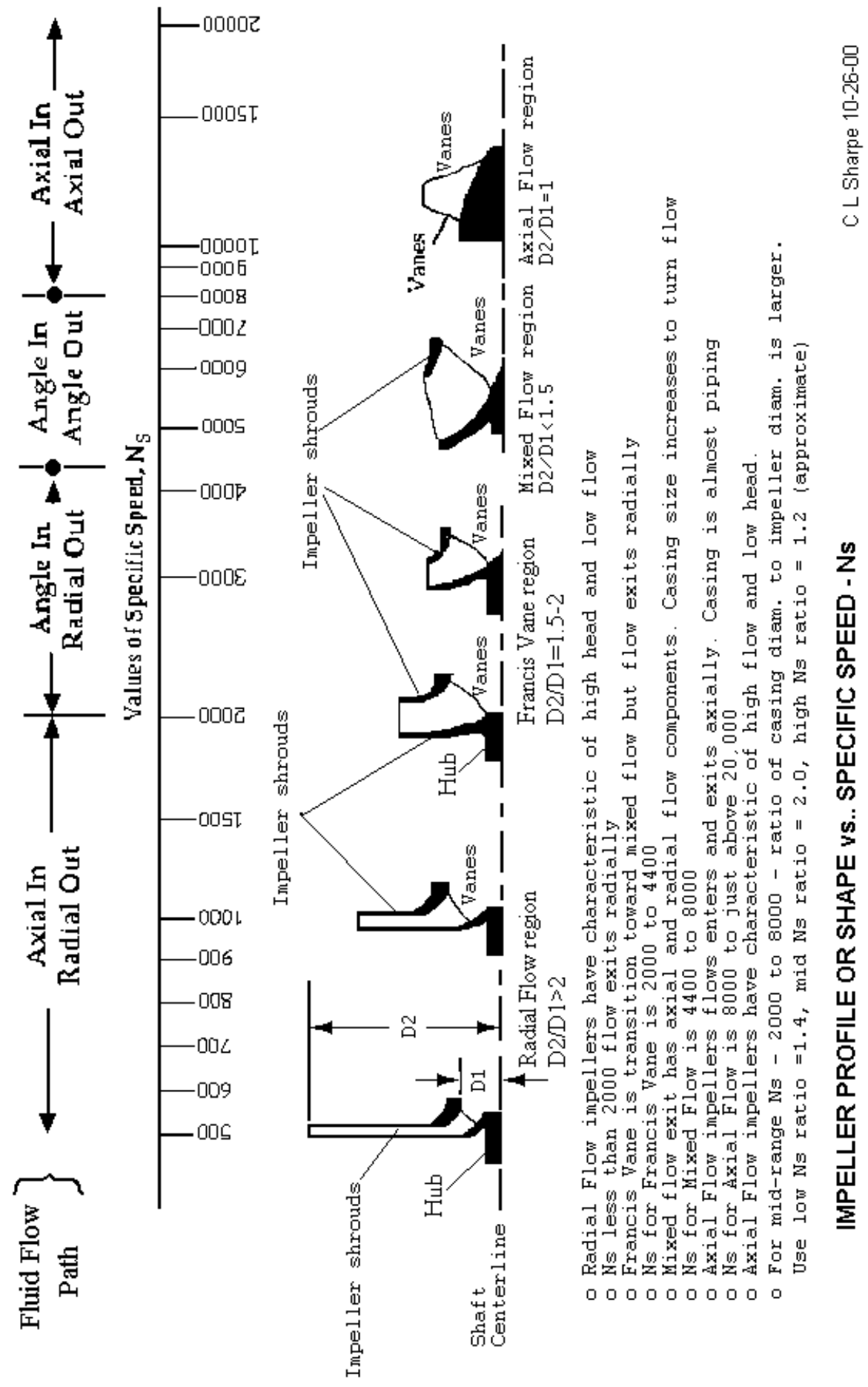

Figure 10. Impeller Profile or Shape vs. Specific Speed - Ns 


\section{Table 4. Scoping Calculation for Pump Mixing at Constant HP}

For 1.2 s.g. 20 wt \% slurry, this provides Uo, UoD, ECR, H (head of pump required for input nozzle diam and one nozzle flow Q. Also calculates HHP, BHP and impeller diam required to produce head at $1750 \mathrm{rpm}$ and one other rpm.

Many impeller diameters at $1750 \mathrm{rpm}$ are unfeasible; choose alternate rpm. Input parameters are nozzle diam. D (in), Q (gpm), and alternate pump rpm.

\begin{tabular}{|c|c|c|c|c|c|c|c|c|c|c|c|c|c|c|c|}
\hline $\begin{array}{l}\text { D } \\
\text { n }\end{array}$ & $\mathrm{ft}$ & m & os & $\mathrm{ft}^{2} / \mathrm{s}$ & $\mathrm{ft}$ & $\mathrm{d} \mathbf{f t}$ & hp & act & hp & limit & 1750 & 1750 & rpm & rpm & P. \\
\hline & & & & 4.544 & 8 & 106 & 1.19 & & & & & & & 443 & \\
\hline & & & 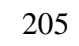 & & 45.2 & 6 & 14 & 0 & 250 & 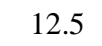 & 20 & & & & \\
\hline & 13 & 7 & & & 36.1 & 4( & 10 & & & .5 & 20 & & & & \\
\hline & & & & 6 & 23.9 & 176 & 31.9 & & 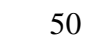 & 12.5 & 13.3 & & & & \\
\hline 2 & 17 & & 5.6 & 26 & 7.5 & 10.6 & 0.8 & 0.6 & 1.33 & 16.7 & 3.25 & 717 & & & \\
\hline 2 & 17 & 1611 & 65 & 27.45 & 48.3 & 439 & 214 & 0.86 & 250 & 16.7 & 21 & & & & 2.2 \\
\hline 2 & & & & & 38.6 & 281 & 110 & & 150 & 16.7 & 16.8 & & & 16.8 & \\
\hline 2 & & & & & 5.6 & & & & 50 & 16.7 & & & & & \\
\hline 3 & & & 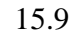 & & 7 & 4.63 & & & & 25 & & & & & \\
\hline 3 & 25 & 2 & 121 & 30.17 & 3.1 & 266 & 214 & 0.86 & 250 & 25 & 16.3 & & & & 68 \\
\hline 3 & 25 & 5 & 96.6 & 24.14 & 42.5 & 170 & 110 & & : & 25 & 13.1 & & & & 10 \\
\hline 3 & & & 6 & & 28.1 & 8 & 31.9 & & 50 & 5 & 8.65 & & & & 81 \\
\hline 4 & & & 28 & & & 3.26 & & & & & & & & & \\
\hline 4 & & & & & & 18 & & & & & & & & & \\
\hline 4 & & & & & & & & & & & & & & & \\
\hline 4 & & & & & & & & & & & & & & & \\
\hline 4 & & & & & & & & & & & & & & & \\
\hline 6 & & & & & & & & & & & & & & & \\
\hline 6 & & & & & & & & & & & & & & & . \\
\hline 6 & & & & & & & & & & & & & & & . \\
\hline 6 & & & & & & & & & & & & & & & 年 \\
\hline 6 & & & & & & & & & & & & & & & (1) \\
\hline 8 & & & & & & & & & & & & & & & 00 \\
\hline 8 & & & & & & & & & & & & & & & 10 \\
\hline 8 & & & & & & & & & & & & & & & 97 \\
\hline 8 & & & & & & & & & & & & & & & 93 \\
\hline & 1 & & & & & & & & & & & & & & 392 \\
\hline & 1 & & & & & & & & & & & & & & 19 \\
\hline & 1 & & & & & & & & & & & & & & 23 \\
\hline & 1 & & & & & & & & & & & & & & \\
\hline & 1 & & & & & & & & & & & & & & \\
\hline 16 & & & & & & & & & & & & & & & \\
\hline 16 & & & & & . & 10.6 & & & & & & & & & \\
\hline 16 & & & & & 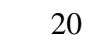 & & & & & 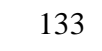 & 1.48 & & & $1-$ & 210 \\
\hline 20 & & & 9.03 & & 26.5 & 2.63 & 7.05 & & & 167 & 1.62 & & 550 & 10.4 & 25000 \\
\hline 0 & 67 & 000 & 1.2 & 18.75 & 33 & 4.09 & 13.6 & 0.62 & 22.1 & 167 & 2.02 & 63854 & 550 & 20.5 & 20068 \\
\hline
\end{tabular}


WSRC-TR-2001-00313

Table 5. Scoping Calculation - ECR vs. $Q$ at Constant BHP

\begin{tabular}{|c|c|c|c|c|c|c|c|c|c|c|c|c|c|c|c|}
\hline $\begin{array}{l}\text { D } \\
\text { in }\end{array}$ & $\begin{array}{l}\text { D } \\
\text { ft }\end{array}$ & $\begin{array}{c}\mathbf{Q} \\
\text { gpm }\end{array}$ & $\begin{array}{l}\text { Uo } \\
\text { fps }\end{array}$ & $\begin{array}{l}\text { UoD } \\
\mathrm{ft}^{2} / \mathrm{s}\end{array}$ & $\begin{array}{c}\text { ECR } \\
\mathbf{f t}\end{array}$ & $\begin{array}{l}\text { Hd ft } \\
\text { Hd ft }\end{array}$ & НHР & $\begin{array}{l}\text { Eff } \\
\text { fract }\end{array}$ & $\begin{array}{c}\text { BHP } \\
\text { hp }\end{array}$ & $\begin{array}{l}\text { jet eq } \\
\text { limit }\end{array}$ & $\begin{array}{l}\text { d1 at } \\
1750\end{array}$ & $\begin{array}{l}\text { Ns at } \\
1750\end{array}$ & $\begin{array}{l}\text { Alter } \\
\text { rpm }\end{array}$ & $\begin{array}{l}\text { d2 at } \\
\text { rpm }\end{array}$ & $\begin{array}{c}\text { Ns at } \\
\text { alt rpm }\end{array}$ \\
\hline .5 & 13 & 1129 & 205 & 25.66 & 45.2 & 626 & 214 & 0.86 & 250 & 12.5 & 25 & 469.9 & 1750 & 25 & 469. \\
\hline 1.5 & 13 & 903.7 & 164 & 20.53 & 36.1 & 401 & 110 & 0.73 & 150 & 12.5 & 20 & 587.3 & 1750 & 20 & 587.3 \\
\hline 1.5 & .13 & 598.7 & 109 & 13.6 & 23.9 & 176 & 31.9 & 0.64 & 50 & 12.5 & 13.3 & 886.5 & 1750 & 13.3 & 386.5 \\
\hline 2 & .17 & 1611 & 165 & 27.45 & 48.3 & 439 & 214 & 0.86 & 250 & 16.7 & 21 & 732.2 & 1750 & 21 & 732.2 \\
\hline 2 & 0.17 & 1289 & 132 & 21.96 & 38.6 & 281 & 110 & 0.73 & 150 & 16.7 & 16.8 & 915.1 & 1750 & 16.8 & 915.1 \\
\hline 2 & 0.17 & 853.7 & 87.3 & 14.55 & 25.6 & 123 & 31.9 & 0.64 & 50 & 16.7 & 11.1 & 1381 & 1750 & 11.1 & 1381 \\
\hline 3 & 0.25 & 2655 & 121 & 30.17 & 53.1 & 266 & 214 & 0.86 & 250 & 25 & 16.3 & 1368 & 1750 & 16.3 & 1368 \\
\hline 3 & 0.25 & 2125 & 96.6 & 24.14 & 42.5 & 170 & 110 & 0.73 & 150 & 25 & 13.1 & 1710 & 1750 & 13.1 & 1710 \\
\hline 3 & 0.25 & 1408 & 64 & 15.99 & 28.1 & 74.8 & 31.9 & 0.64 & 50 & 25 & 8.65 & 2581 & 1750 & 8.65 & 2581 \\
\hline 4 & 0.33 & 3786 & 96.8 & 32.26 & 56.8 & 187 & 214 & 0.86 & 250 & 33.3 & 13.7 & 2132 & 1750 & 13.7 & 2132 \\
\hline 4 & 0.33 & 3030 & 77.4 & 25.81 & 45.4 & 120 & 110 & 0.73 & 150 & 33.3 & 10.9 & 2664 & 1750 & 10.9 & 2664 \\
\hline 4 & 0.33 & 2007 & 51.3 & 17.1 & 30.1 & 52.5 & 31.9 & 0.64 & 50 & 33.3 & 7.24 & 4021 & 1150 & 16.8 & 2643 \\
\hline 4 & 0.33 & 1576 & 40.3 & 13.43 & 23.6 & 32.4 & 15.5 & 0.62 & 25 & 33.3 & 5.69 & 5120 & 1150 & 13.2 & 3364 \\
\hline 6 & 0.5 & 6243 & 70.9 & 35.47 & 62.4 & 113 & 214 & 0.86 & 250 & 50 & 10.6 & 3983 & 1750 & 10.6 & 3983 \\
\hline 6 & 0.5 & 4995 & 56.8 & 28.38 & 49.9 & 72.5 & 110 & 0.73 & 150 & 50 & 8.52 & 4978 & 1750 & 8.52 & 4978 \\
\hline 6 & 0.5 & 4995 & 56.8 & 28.38 & 49.9 & 72.5 & 110 & 0.73 & 150 & 50 & 8.52 & 4978 & 1150 & 19.7 & 3271 \\
\hline 6 & 0.5 & 3309 & 37.6 & 18.8 & 33.1 & 31.8 & 31.9 & 0.64 & 50 & 50 & 5.64 & 7514 & 1150 & 13.1 & 4937 \\
\hline 8 & 0.01 & 8902 & 56.9 & 37.93 & 66.8 & 79.4 & 214 & 0.86 & 250 & 66.7 & 8.91 & 6206 & 1150 & 20.6 & 4078 \\
\hline 8 & 0.67 & 7123 & 45.5 & 30.35 & 53.4 & 50.9 & 110 & 0.73 & 150 & 66.7 & 7.13 & 7756 & 1150 & 16.5 & 5097 \\
\hline 8 & 0.67 & 4719 & 30.2 & 20.1 & 35.4 & 22.3 & 31.9 & 0.64 & 50 & 66.7 & 4.72 & 11707 & 1150 & 10.9 & 7693 \\
\hline 12 & 1 & 14679 & 41.7 & 41.69 & 73.4 & 48.2 & 214 & 0.86 & 250 & 100 & 6.94 & 11595 & 1150 & 16.1 & 7619 \\
\hline 12 & 1 & 11744 & 33.4 & 33.36 & 58.7 & 30.8 & 110 & 0.73 & 150 & 100 & 5.55 & 14492 & 1150 & 12.9 & 9523 \\
\hline 12 & 1 & 7781 & 22.1 & 22.1 & 38.9 & 13.5 & 31.9 & 0.64 & 50 & 100 & 3.68 & 21874 & 850 & 15.6 & 10625 \\
\hline 12 & 1 & 5662 & 16.1 & 16.08 & 28.3 & 7.17 & 12.3 & 0.61 & 20 & 100 & 2.68 & 30062 & 850 & 11.3 & 14602 \\
\hline 16 & 1.33 & 12743 & 20.4 & 27.14 & 47.8 & 12.5 & 48.4 & 0.66 & 73.5 & 133 & 3.54 & 29675 & 850 & 15 & 14414 \\
\hline 16 & 1.33 & 5335 & 8.52 & 11.37 & 20 & 2.2 & 3.55 & 0.6 & 5.87 & 133 & 1.48 & 70877 & 550 & 15 & 22276 \\
\hline 20 & 1.67 & 7559 & 7.73 & 12.88 & 22.7 & 1.93 & 4.42 & 0.61 & 7.3 & 167 & 1.39 & 92921 & 550 & 14.1 & 29204 \\
\hline 20 & 1.67 & 10212 & 10.4 & 17.4 & 30.6 & 3.52 & 10.9 & 0.61 & 17.8 & 167 & 1.88 & 68783 & 550 & 19 & 2161 \\
\hline
\end{tabular}




\section{$\underline{\text { Appendix }}$}

This appendix is mostly of interest to someone who wishes to duplicate the spreadsheet or who wishes to improve on the scoping aids by refining the relationships.

\section{$\underline{\text { Methodology for Creating Spreadsheet and Graph }}$}

Choose three parameters that would describe the pump function as usefully as possible. One of the three would be a function of the other two (called given parameters). Draw a graph with the dependent parameter a function of one independent parameter and the second parameter exhibited as a family of lines. In this case the Effective Cleaning Radius -ECR - was chosen as the dependent parameter (y-axis on graph). The first independent parameter is flow through a single nozzle $-\mathrm{Q}$ (x-axis on graph). The second independent parameter is nozzle diameter - D - with a family of lines of ECR vs. Q for different nozzle diameters. The given (or input) parameters were chosen so that other parameters describing mixer pump function or characteristics could be calculated from the initial given parameters. Key functions to be calculated were ECR and the head - $\mathrm{H}-$ required from the pump.

\section{Sources of Relationships and Baseline Data}

Mathematical relationships were from two sources. Published relationships were used as is or simplified to define a "middle of the road" process situation. For other relationships known or measured values of pump properties and ECR were used to define empirical, easily calculated relationships. It is recognized that these are not precise. They are close enough to use for evaluation or what might be called "scoping." The specific baseline data are tabulated next. The ECR is assumed to apply to a fluid with 1.2 weight \% solids and $1.2 \mathrm{sp}$. gr. - this makes some allowance for the liquid being salt solution.

\begin{tabular}{|l|l|l|l|l|l|}
\hline Pump & Flow Q gpm & Nozzle D in. & Head ft. & ECR ft. & RPM N \\
\hline Standard SP & 600 & 1.5 & 190 & 25 & 1750 \\
\hline QVSP early & 2000 & 3.0 & 145 & 40 & 2200 \\
\hline QVSP later & 2600 & 3.62 & 120 & NA & 2200 \\
\hline ADMP & 5250 & 6.0 & 60 & 50 & 1150 \\
\hline Tank 48 at 900 & 450 & 1.62 & 68 & NA & 900 \\
\hline Flygt Mixer & NA & 19.5 & NA & 30 & 550 \\
\hline
\end{tabular}

\section{Calculated Parameters}

The calculated parameters are listed next. The source of the relationship is listed as: 1) precise, 2) established, 3) simplified or 4) empirical. In some cases, subsequent paragraphs describe the logic in more detail.

Uo - jet velocity leaving nozzle $-\mathrm{ft} . / \mathrm{sec}$. $\mathrm{Uo}=\mathrm{f}(\mathrm{Q}, \mathrm{D})$ - precise

$\mathrm{UoD}=\mathrm{f}(\mathrm{Q}, \mathrm{D})-$ precise

$E C R=f(Q, D)-$ simplified and empirical

$H$ - head require from pump to provide flow $Q$ with nozzle $D . H=f(Q, D)$ - empirical

HHP - hydraulic horsepower. HHP $=\mathrm{f}(\mathrm{Q}, \mathrm{D}$, sp.gr. $)$ - established

Eff - pump efficiency - empirical

BHP - brake horsepower. BHP $=\mathrm{f}(\mathrm{HHP}, \mathrm{eff})$ - precise

D1 - impeller diameter at $1750 \mathrm{rpm}$ - established as an approximation

D2 - impeller diameter at an alternate rpm (to be input) - established

Ns1 and Ns2 - specific speed for pumps with impellers D1 and D2 


\section{Precise or Established Relationships}

$\mathrm{Uo}=0.409 * \mathrm{Q} / \mathrm{D}^{2}$

$\mathrm{UoD}=\mathrm{Uo}^{*} \mathrm{D}$

$\mathrm{HHP}=\mathrm{Q} * \mathrm{H} *$ sp.gr. $/ 3960$

$\mathrm{BHP}=\mathrm{HHP} /$ eff

$\mathrm{D} 1=\mathrm{H}^{0.5}$

$\mathrm{D} 2=\mathrm{D} 1 *(\mathrm{rpm} / 1750)^{2}$

\section{$\underline{\text { Effective Cleaning Radius }}$}

ECR is also actually a function of density, yield stress and an established empirical constant for turbulent free jet flow. Assuming the salt solution slurry given above the equation reduces to a linear equation. The best fit to the baseline data is very good.

$\mathrm{ECR}=1.76 * \mathrm{UoD}$

\section{Pump Head Requirement}

The pressure drop through a nozzle should be proportional to the square of flow and inversely proportional to the nozzle diameter to a power of four or slightly less. The best fit to the baseline was for power $n=3.7$. All other physical and fluid properties are combined in a single constant.

$\mathrm{H}=0.00228 \mathrm{Q}^{2} / \mathrm{D}^{3.7}$

\section{Pump Efficiency}

A curve exists showing pump efficiency as a function of Specific Speed Ns and Flow Q. Efficiencies range from 0.6 (small pumps) to 0.9 (large pumps). Since this is a scoping calculation a simple linear relationship was defined. The equation can incorrectly calculate an efficiency higher than 1.0 but this is beyond the range if interest.

Eff $=0.6+0.3 * \mathrm{HHP} / 250$

\section{Pump Brake Horsepower}

Brake horsepower is closer to the motor size and motor size can be looked up in suppliers' literature. This is the reason for including it in the data instead of hydraulic horsepower. This is also the reason pump efficiency was estimated.

\section{$\underline{\text { Jet Equation Limit }}$}

This is not shown but the approximation is easy to calculate. The turbulent free jet equation in Perry's Chem E Handbook is valid to 100 nozzle diameters. Additionally the mixing radius in the baseline data makes the use of the equation appear valid to at least 200 nozzle diameters. This is probably of little interest in scoping work but should be acknowledged. 


\section{$\underline{\text { Required Impeller Diameter }}$}

A fairly accurate equation derived from energy relations results in the equation

$\mathrm{H}-\mathrm{ft}=\mathrm{D}^{2}$

where $\mathrm{D}$ is in inches if the speed is $1750 \mathrm{rpm}$. The constants work out to about unity. In this work the equation was solved for D (D1). The pump affinity laws provide the way to adjust for different speeds. Impeller diameter at a new speed is proportional to the square of the ratio of new speed to 1750. For large flows and low heads, the initial calculation D1 is unfeasible as a physical pump. D2 is a more valid value for these conditions. Since the affinity laws derive from the same energy relations the double approximation loses no accuracy.

\section{Specific Speed and Pump Size}

Specific Speed is a design parameter that defines the physical characteristics of the impeller. This in turn defines the characteristics of the pump casing. The second figure provides this data.

\section{Flygt Mixer}

The hydraulic properties of the Flygt Mixer were obtained using the EXCEL spreadsheet. Nozzle diameter was set at $19.5 \mathrm{in}$. Alternate rpm was set at 550. The second impeller diameter D2 was targeted at $19.3 \mathrm{in}$. EXCEL will calculate a flow to provide the target impeller diameter. The calculated flow was 10,000 gpm. 10,000 gpm is the same as the flow estimated from pitot tube velocity taken at the nozzle exit. Other properties such as Head, Uo, and BHP follow. The BHP is also in line with the actual test value.

\section{Acknowledgements}

Thanks to Erich Hansen for helping me with EXCEL. 
WSRC-TR-2001-00313

\title{
10.0 APPENDIX C
}

\section{CHRONOLOGY OF PUMP RUN INS FOR \\ TANK 8 MIXER PUMPS}

\section{PLUS \\ RECOMMENDED PROGRAM FOR TANKS 7 AND 11 MIXER PUMPS WITH EXPLANATIONS AND JUSTIFICATION}

\author{
Tank 8 Tank 7/11 LPI slurry pump summary for T. M. Monahon C. L. Sharpe 3-8-00 \\ HISTORY
}

10-96 Part of specification acceptance testing. Run 8 hrs. at LPI and run $260 \mathrm{hrs}$. at SN1 run SRS. Disassembled and inspected. Very satisfactory, high expectations for remainder of order. Remainder of pumps run $8 \mathrm{hrs}$. at LPI.

06-98 Start run ins for Tank 8. Acceptance criteria based on spec, i.e. motor and prox SN2 run probe. Column vibrations monitored - results high. Resonance at $1780 \mathrm{rpm}$ observed. Argument presented to stop run before damaging pump.

06-98 Column vibrations lower. $72 \mathrm{hrs}$. completed. No negative trends. Resonance SN5 run at 1780 rpm observed and need for VFDs and lower speed recognized but run completed at $1780 \mathrm{rpm}$ with reservations. First acceptable pump.

07-98 Same as SN5. Second acceptable pump.

SN6 run

07-98 Same as SN2. Not acceptable. Motor only run; no help. Short run.

SN7 run

07-98 Vendor and consultant help sought. No magic fixes. Argument presented for

Run ins VFDs and lower speed operation and run ins. Decision forced on willingness to stopped to commit pumps to waste tank. Agreed to use those with less than 0.2 ips column assess plus tightened criteria on other measurements. Decided that even $72 \mathrm{hr}$. run in situation at $1780 \mathrm{rpm}$ inadvisable in spite of some successes. 
10-98 Same as SN2. Not acceptable. Short run. 3 of 5 to date unacceptable.

SN3 run

11-98 This had been OK in 1996. Marginal column vibration. Other vibrations not as SN1 run good as in 1996. Continued to run. Vibration trended up by $48 \mathrm{hr}$. Column water black. Later found shaft worn. 4 of 6 to date unacceptable.

11-98 Started up bad; made good by changing alignment procedure. $72 \mathrm{hrs}$. competed. SN4 run 3rd acceptable pump.

12-98 SN6 retested to see if acceptable still acceptable. OK. Still 3 acceptable pumps.

12-98 Consultants convened try to define cause of problem without any examination of pumps to date. Additional design and data review.

01-99 4th good pump.

SN 8 run

09-99 Found stuck shafts in Tank 8. Problem resolved but creates slightly higher risk estimate on pump reliability.

RECOMMENDED ACTIONS for remaining 9 pumps - including 4 rejects (one damaged for sure) and 5 untested.

1 Repair a lower shaft with acceptable sleeve; either 410 SST or MTS recommendation. In parallel, corrosion and abrasion tests on MTS recommended material.

2 Design and build tilting pad bearings fitting existing housings for one pump with provision for dimensional changes.

3 Build new split retainers.

4 In parallel, contract two rotordynamic analyses of pump plus modifications.

5 Measure and correct casing non-uniformity.

6 Disassemble, measure, and reassemble modified pump with particular attention to alignment.

7 Test modified pump, analyze results, disassemble and inspect if necessary. 
GENERAL EXPLANATIONS, NOTES AND ARGUMENTS about recommendations

A Issue with reject pumps is rotordynamics and resonance.

B HLW/SRTC Material Test Group has selected Stellite as preferred material for sleeve and to replace Sic product lubricated bearing; probably not essential.

C Doing nothing to future shafts is not a defensible option; Tank 8 decision to "use as is" brings in some risk on reliability because product lubricated bearing is compromised. Risk assessment favored "use as is" compared against very risky rad work and unknown reliability after rework.

D Pump inventory is 4 rejects from Tank 8 (rejection criteria was proved with SN1) plus 5 untested pumps.

E Probability of getting 4 usable pumps with "Tank 8 - test another pump" approach is almost zero.

F LPI's design philosophy and assembly methods are same as other suppliers (Sulzer Bingham, Inc., Hazleton Pumps, Inc. and Floway Pumps); i.e. machine to tight tolerances and assemble without any special methods or adjustments. This is acceptable for most of their business; it is part of the problem for SRS pumps. The machine and assembly tolerances are in the ball park of the alignment, shaft unbalance, and bearing differences that result is variable success - some OK, some not. This has happened at all four suppliers with the possible exception of Hazleton. There are some supplier design detail differences that may enter the picture, but not enough study has been done for this to be more than hypothesis.

G For the remaining nine pumps, four have to be disassembled. Of the untested five pumps, two or three are likely to require disassembly also. The big cost in preparing and proving the pumps acceptable for use is going to be labor. Based on our current understanding of the problem (A above), recommended actions directed at vibration should result in a very high probability of approval on the first test. Not doing these actions will very likely drive up labor costs beyond the cost of the recommended actions. Details on individual recommendations are below. 
BASIS FOR RECOMMENDED ACTIONS - numbers correspond to actions above

1 Sleeve lower shaft. See C above. "Use as is, meaning corroded" was defensible for pumps already in waste tank. For pumps not in tank, the risk of compromised product lube bearings is not worth the relatively low cost to correct. At a minimum, each pump can be sleeved with a 410SSST sleeve for about $\$ 3 \mathrm{~K}$ each; use existing SiC bushing. Better is to follow MTS recommendation which is Stellite on Stellite. Added cost per pump is about $\$ 1 \mathrm{~K}$.

Parallel corrosion and abrasion tests on MTS recommended material and other materials. Not doing these tests involves only minor risk, in my opinion, because of the $100 \mathrm{hr}$. test with brass for EFP. The shaft didn't contact the bushing. But MTS feels more strongly, that for slurry use as opposed to water or salt solution, the tests are essential and this is their field. Also, this data is needed for future specifications even if we opt for 410SST. My personal vote is to let schedule determine for Tank 11. Use Stellite if we can get it in time.

2 Tilting pad column bearings. There is data to back this up. First, journal bearings in a vertical pump are going to have shaft whirl to some degree. This is the $1 / 2 \mathrm{X}$ component referred to in vibration. For the eight LPI pumps, we did a correlation study of vibration parameters associated with the "good pump/bad pump" categories. The best correlation was low $1 / 2 \mathrm{X}$ component. This varies with the loading on the bearings. Bearing load varies with the very small alignment differences from pump to pump. But it is not predictable. To be predictable, a different type of bearing is needed. The consultants have been very consistent on this point and the tilting pad design has been most often mentioned by the consultants and in pump literature recently. To do otherwise, such as try to use the existing journal bearings, will almost certainly involve disassembly, alignment, testing and then more disassembly and more testing. This is the path taken on the EFP and it was time consuming. There might be a couple of early successes probably offset by a couple of real problems. In the end, labor costs are going to greatly exceed the cost of new bearings. To consider running pumps at high column vibration levels is contradicted by experience; LPI SN1 retest, Sulzer Tank 40 order, and Floway West Valley are all evidence of very short life with high column vibration.

3 New split retainers. This is an item that might be optional. But the cost is low - about $\$ 2 \mathrm{~K}$ per pump. The EFP showed that shaft misalignment can result. This causes unbalance which is also a vibration factor. Installing shims in the existing retainers is a possible action but it seems makeshift in the overall picture.

4 Rotordynamic analysis. This provided very valuable insight into the EFP pump vibration performance and aided decision making on paths forward. This was particularly true for the decision to go ahead and install the pump. Not doing this analysis is technically unsound. It is approved for TFA funds and underway. 
5 Casing non-uniformity. One casing was found to be a maximum of 0.2 inch nonuniform in the internal radial direction. This is caused by a mold shift in the casting process. We observed the consistent presence of a $5 \mathrm{X}$ vibration component and were searching for an explanation. In at least one pump this was a significant contribution to the total vibration level. The impeller has 5 vanes but the impeller is very uniform. We believe we have found a problem. Recent comparison of vibration data from all 8 pumps against the "good pump/bad pump" breakdown appears to show higher $5 \mathrm{X}$ energies in the "bad" pumps. It is not a "yes/no" correlation. We have only examined one casing. We have not completely examined any pump yet because of the EFP pump last year and now funding.

$6 \& 7$ testing is fundamental. The decision to disassemble and inspect a pump will depend on vibration observations after incorporating the recommended actions. It is a desirable step but omission could be justified in balancing good performance vs. funding. 
This page intentionally left blank.

Page 56 of 58 


\subsection{REFERENCES}

${ }^{1}$ Franklin, Wes, "Rotordynamic Model for RHLWE EFP,” BN-99-1008, 10/18/1999.

${ }^{2}$ Franklin, Wes, “Rotordynamic Analysis LPI91103,” BN-00-0627, 6/27/2000.

${ }^{3}$ Corbo, Mark, "LPI91103 Bearing and Rotor Analysis,” NBE-00-0926, 6/26/2000.

${ }^{4}$ Corbo, Mark, “Pump Rotordynamics Made Simple,” Corbo-98-1231, 12/31/1998.

${ }^{5}$ Karassik, Igor, "Pump Handbook - $2^{\text {nd }}$ edition, McGraw Hill," Karassik-86, 1/1/1986.

${ }^{6}$ Baladi, J. Y., and Sharpe, C. L., "SP and Mechanical Seal Development Review," WSRCTR-94-0450, 9/27/1994.

${ }^{7}$ Dalmaso, M. J., “HLW Evaporator Transfer Pump Status,” IWT-LWP-89-0027, 6/12/1989.

${ }^{8}$ Dalmaso, M. J., and Fazio, J. M., “SP Impeller Hub and Breakdown Bush Wear,” WSRCRP-90-1277, 11/15/1990.

${ }^{9}$ Dalmaso, M. J., and Sharpe, C. L., "5-axis Machined Impellers for SP, Dalmaso-96-0907, 9/6/1996.

${ }^{10}$ Dalmaso, M. J., et. al., "Prep and Test of Tank 51 Replacement SPs," WSRC-RP-96-53, 1/31/1996.

${ }^{11}$ Sharpe, C. L., “ESP Pump Recommendations,” WER-HLE-94-1348, 4/19/1994.

12 Sharpe, C. L., and Pourier, M. R., "Impact of QVSP Jet Forces on Tank 51 Coils," SRTWHM-95-051, 9/26/1995.

${ }^{13}$ Sharpe, C. L., "SRS Assistance of WVNS Floway Order,” Sharpe-98-0605, 6/5/1998.

${ }^{14}$ Sharpe, C. L., and Stefanko, “3H Replacement Evaporator Feed Pump,” WSRC-TR-200100312, June 2001.

${ }^{15}$ Waters, E. D., “ADMP Specification,” WHC-S-0211, 11/29/1993.

${ }^{16}$ Healy, J. J., “Review of ADMP Specification,” TLSR-FC-2136, 7/5/1994.

${ }^{17}$ Dalmaso, M. J., “ADMP Final Design Review,” SRT-WHM-95-0052, 9/15/1995.

${ }^{18}$ McKeel, C., “ADMP and Full Tank Structural Analysis,” Memo to Sharpe, 10/7/1998. 
This page intentionally left blank.

Page 58 of 58 